\title{
Pharmacokinetic Investigation of Commercially Available Edible Marijuana Products in Humans: Potential Influence of Body Composition and Influence on Glucose Control
}

Taylor Russell Ewell ${ }^{1}$, Kieran Shay Struebin Abbotts ${ }^{1}$, Natasha N. Bondareva Williams ${ }^{1}$, Hannah Michelle Butterklee ${ }^{1}$, Matthew Charles Bomar ${ }^{1}$, Kole Jerel Harms ${ }^{1}$, Jordan Douglas Rebik $^{1}$, Sarah Margaret Mast ${ }^{1}$, Natalie Akagi ${ }^{2}$, Gregory P. Dooley ${ }^{2}$, and Christopher Bell ${ }^{1 *}$

${ }^{1}$ Department of Health and Exercise Science, Colorado State University, Fort Collins, CO 80523-1582, USA

${ }^{2}$ Department of Environmental and Radiological Health Sciences, Colorado State University, Fort Collins, CO 80523-1680, USA

*Corresponding Author:

Christopher Bell, Ph.D., Department of Health and Exercise Science, Colorado State University, Fort Collins, CO 80523-1582, USA. Email: christopher.bell@,colostate.edu Telephone: 970491-7522

Funding: Stillwater Brands, Colorado, USA

The purpose of the study was to describe and compare the pharmacokinetics of five commercial edible marijuana products, determine the influence of body composition on pharmacokinetics, and, in light of epidemiology suggesting marijuana may offer diabetes protection, explore the influence of edible marijuana on glucose tolerance. Seven regular users of marijuana selfadministered five edible products in a randomized crossover design; each product contained $10 \mathrm{mg}$ of delta-9-tetrahydrocannabinol (THC). 30-minutes following marijuana ingestion, participants imbibed a $75 \mathrm{~g}$ glucose beverage. Time-to-peak plasma THC concentration ranged between 35 and 90 minutes; maximal plasma THC concentration $\left(\mathrm{C}_{\max }\right)$ ranged between 3.2 and $5.5 \mathrm{ng} / \mathrm{mL}$. Differences between products in plasma THC concentration during the first 20-to-30 minutes were detected $(P=0.019)$. Relations were identified between body composition and pharmacokinetic parameters for some products; however, none of these body composition characteristics were consistently related to pharmacokinetics across all five of the products. Edible marijuana had no effect on oral glucose tolerance compared with a marijuana-free control (Matsuda Index; $P>0.395$ ). Commercially available edible marijuana products evoke different plasma THC concentrations shortly after ingestion, but do not appear to influence acute glucose regulation. These data may allow marijuana users to make informed decisions pertaining to rates of edible marijuana ingestion and avoid overdose.

Keywords: cannabis, cannabinoid, diabetes, insulin 
Legal access to marijuana, derived from the plant Cannabis sativa L. is increasing. To illustrate, within the USA, at the time of manuscript submission, marijuana is approved for recreational and medicinal use in 18 and 36 of the 50 states, respectively. Internationally, recreational use of marijuana is permitted in Uruguay, Canada, Georgia and South Africa, and marijuana possession has been decriminalized in many countries, including most throughout South America. Accompanying increased access to marijuana are the number of options for mode of consumption. While inhalation of combusted marijuana remains common $[1,2]$, the consumption of marijuana via commercially available edible (oral) products is becoming more prevalent. This increase in edible consumption is not without implication. The incidence of edible marijuana overdose reported to United States poison centers is also increasing (e.g. 5fold increase between 2013 and 2015), the symptoms of which range in severity from mild anxiety and lethargy, to respiratory depression [3]. The increase in overdose prevalence has been attributed to two factors: accidental/unintentional ingestion (i.e. the patient was unaware they were ingesting marijuana) most common in children [4,5], and repeated premature dosing because of the absence of an immediate sensation of altered psychoactive state [6,7]. That is, compared with inhalation, the time to perceived effects of the edible marijuana are appreciably delayed [8]. Unfortunately, detailed studies describing the variability in the pharmacokinetics of the psychoactive component $(\Delta-9$-Tetrahydrocannabinol (THC)) and its metabolites (11hydroxytetrahydrocannabinol (THC-OH) and 11-nor-9-carboxytetrahydrocannabinol (THC$\mathrm{COOH})$ ) from commercially available edible marijuana products are lacking.

Studies that have quantified circulating THC concentration following marijuana ingestion have yielded highly variable results [8-10]. Several explanations have been proposed to explain this variability, one of which includes differences in the composition of the edible product. For example, while additional ingredients and/or macro-nutrients within the product, such as the fat and/or protein in marijuana brownies, may enhance the flavor, they may also influence the rate of THC absorption from the gut. Additionally, the body composition of the edible marijuana consumer may have an influence on pharmacokinetics. Case in point, cannabidiol (CBD) is a non-psychoactive component of Cannabis sativa L.; the time to maximal circulating CBD concentration $\left(\mathrm{T}_{\max }\right)$ following ingestion of a commercial oral CBD preparation is related to fat free mass $\left(\mathrm{R}^{2}=0.365\right)[11]$. Further, adiposity may also influence the pharmacokinetics of THC absorption on account of the lipophilic properties of THC [12].

Aside from recreational use, marijuana and other Cannabis sativa L. products have been purported to have multiple medicinal benefits $[13,14]$. These include pain management[15], the treatment of Inflammatory Bowel Disease [16] and epilepsy [17], decreased nausea associated with some cancer medications [18], and potential protection from diabetes [19-23]. The latter claim is based on large epidemiological studies reporting on decreased incidence of diabetes in habitual and former marijuana users. With the exception of three conflicting studies completed in the 1970's [24-26], very few carefully controlled and laboratory-based investigations exploring the direct influence of marijuana on glucose control have been completed. These older studies involved intravenous THC administration, and inhalation of combusted marijuana. Compared with Cannabis sativa L. plants grown in the 1970's, present day genetically-modified strains and modern cannabis products typically have greater THC potency [27]. Further, intravenous administration is not reflective of contemporary marijuana use [1,2]. Additional explanations for the relative paucity of controlled, laboratory-based studies include the current legal and ethical complications associated with the administration of marijuana to human research participants. However, several investigators have developed creative solutions for the study of marijuana use 
in humans while remaining compliant with local and federal laws [28]. These have typically involved field-based studies of self-administration of marijuana, or "naturalistic observation" studies.

The current study has several aims: (1) To describe the pharmacokinetics of circulating THC, two of its metabolites (THC-OH and THC-COOH), and the metabolite to parent ratio, following ingestion of commercially available edible marijuana products. This information will provide the marijuana consumer with guidelines as to the timing of marijuana absorption and thereby may prevent overdose. (2) To compare the pharmacokinetics of several different commercially available edible marijuana products. This will also provide the consumer with potentially important information as to differences between the strength and the pharmacokinetics of different products, even when standardized for THC content. (3) To determine the influence of body composition on THC pharmacokinetics. (4) To explore the potential acute influence of edible marijuana on glucose regulation.

\section{RESULTS}

Participants

The progress of all participants throughout the trial (from screening and enrollment through to completion) is presented in Figure 1. A total of 15 participants were enrolled in the study, but only 7 completed all procedures associated with the crossover design. 8 participants either withdrew or were excluded from the study for a variety of reasons that were not necessarily mutually exclusive. These included difficulties with phlebotomy $(n=2)$, an accident unrelated to the study requiring corrective surgery $(n=1)$, inability to refrain from marijuana use prior to study visits $(n=1)$, and voluntary withdrawal on account of poor tolerance of the research protocol $(n=4)$. Selected physiological characteristics of the remaining participants are presented in Table 1. Consistent with inclusion and exclusion criteria, the physiological characteristics were unremarkable.

Table 1. Selected physiological characteristics of study participants.

\begin{tabular}{lcc}
\hline & Mean \pm SD & Range \\
\hline Sex (M/F) & $4 / 3$ & - \\
Age (years) & $31 \pm 5$ & $24-39$ \\
Height (cm) & $170 \pm 11$ & $159-193$ \\
Body Mass (kg) & $82.3 \pm 17.7$ & $62.7-113.9$ \\
Body Mass Index $\left(\mathbf{k g} / \mathbf{m}^{\mathbf{2}}\right)$ & $28.6 \pm 6.5$ & $23.0-40.8$ \\
Fat Mass (kg) & $28.1 \pm 13.5$ & $16.3-55.6$ \\
Body Fat (\%) & $33.4 \pm 10.1$ & $21.2-48.9$ \\
Lean Mass (kg) & $52.2 \pm 10.0$ & $38.1-66.0$ \\
Bone Mineral Content $(\mathbf{k g})$ & $2.3 \pm 0.4$ & $2.0-3.1$ \\
\hline
\end{tabular}




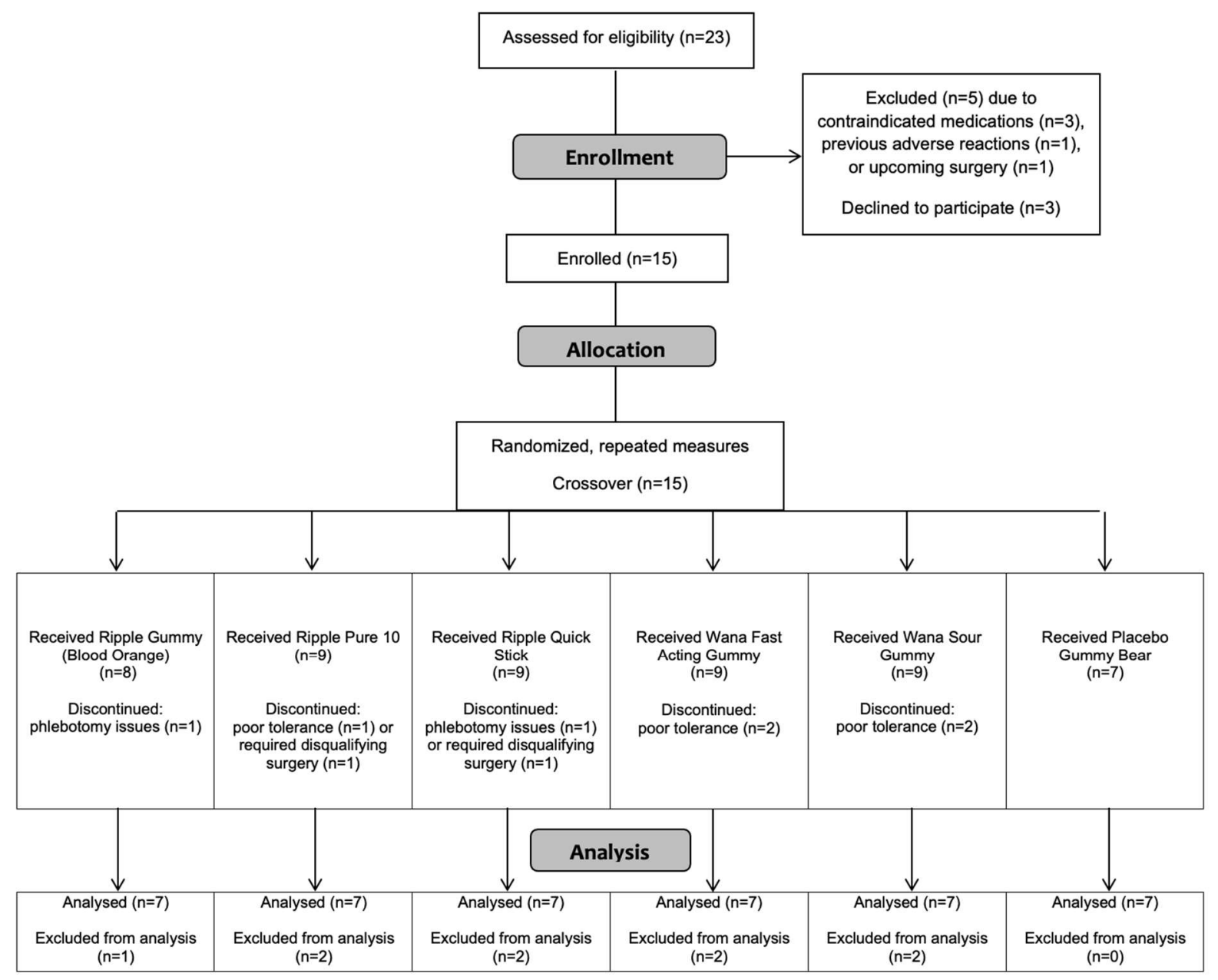

Figure 1. Consolidated Standards of Reporting Trials (CONSORT) flow diagram.

\section{Pharmacokinetics}

Features of each of the edible marijuana products are presented in Table 2. The mean circulating concentrations of THC, THC-OH and THC-COOH are displayed in Figures 2, 3 and 4 , respectively. For THC (Figure 2), there was a product $\mathrm{x}$ time interaction $(P=0.019)$. Post-hoc analysis revealed circulating THC concentration was greater in Ripple Blood Orange Gummies vs. Wana Fast Acting Gummies $(\mathrm{P}=0.003)$ and Wana Sour Gummies $(P<0.001)$ at 20 minutes, and greater in Ripple Blood Orange Gummies vs. Wana Sour Gummies $(P=0.002)$, and Ripple Pure 10 vs. Wana Sour Gummies $(P=0.038)$ at 30 minutes. There were no product $\mathrm{x}$ time interactions for THC-OH $(P=0.415)$ and THC-COOH $(P=0.485)$. 
Table 2. Features of the commercially available edible marijuana products

\begin{tabular}{|c|c|c|}
\hline $\begin{array}{l}\text { Product and } \\
\text { manufacturer }\end{array}$ & Nutrition & Ingredients \\
\hline $\begin{array}{l}\text { Ripple Blood Orange } \\
\text { Gummies (Stillwater } \\
\text { Brands, Commerce } \\
\text { City, CO, USA) }\end{array}$ & $\begin{array}{l}20 \text { kcal per serving: } 2 \\
\text { gummies; (Fat } 0 \text { g, Total } \\
\text { carbohydrate } 4 \text { g, Protein } 0 \\
\text { g) }\end{array}$ & $\begin{array}{l}\text { Glucose syrup, sugar, water, fruit juice } \\
\text { concentrates (Apple, Pear), gelatin, modified } \\
\text { food starch, Ripple (water, modified food } \\
\text { starch, cannabinoid extracts, MCT oil), contains } \\
2 \% \text { or less of: natural flavors, malic acid, citric } \\
\text { acid, carnauba wax, vegetable juice for color }\end{array}$ \\
\hline $\begin{array}{l}\text { Ripple Pure } 10 \\
\text { (Stillwater Brands, } \\
\text { Commerce City, CO, } \\
\text { USA) }\end{array}$ & $\begin{array}{l}0 \mathrm{kcal} \text { per serving }(\text { Fat } 0 \mathrm{~g} \text {, } \\
\text { Total carbohydrate } 0 \mathrm{~g}, \\
\text { Protein } 0 \mathrm{~g})\end{array}$ & $\begin{array}{l}\text { Sorbitol, modified food starch, cannabinoid } \\
\text { extracts, MCT oil }\end{array}$ \\
\hline $\begin{array}{l}\text { Ripple Quick Sticks } \\
\text { Blueberry } \\
\text { Pomegranate } \\
\text { (Stillwater Brands, } \\
\text { Commerce City, CO, } \\
\text { USA) }\end{array}$ & $\begin{array}{l}5 \text { kcal per individual } \\
\text { serving (Fat } 0 \mathrm{~g} \text {, Total } \\
\text { carbohydrate } 1 \mathrm{~g} \text {, Protein } 0 \\
\mathrm{~g} \text { ) }\end{array}$ & $\begin{array}{l}\text { Ripple (Sorbitol, Modified Food Starch, } \\
\text { Cannabinoid Extracts, MCT Oil), Sugar, } \\
\text { Fructose, Natural Flavors, Citric Acid, Malic } \\
\text { Acid }\end{array}$ \\
\hline $\begin{array}{l}\text { Wana Fast Acting } \\
\text { Gummies, Pina } \\
\text { Colada Indica (Wana } \\
\text { Brands, Boulder, CO, } \\
\text { USA) }\end{array}$ & $\begin{array}{l}30 \text { kcal per serving: } 2 \\
\text { gummies (Fat } 0 \mathrm{~g} \text {, Total } \\
\text { carbohydrate } 8 \mathrm{~g} \text {, Protein } 0 \\
\text { g) }\end{array}$ & $\begin{array}{l}\text { Organic Cane Sugar, Organic Tapioca Syrup, } \\
\text { Pectin (Pectin, Potassium Sodium Tartrate, } \\
\text { Polyphosphate, Sucrose), Citric Acid, Natural } \\
\text { Flavoring, Sodium Citrate, Modified Food } \\
\text { Starch, Xanthan Gum, THC. }\end{array}$ \\
\hline $\begin{array}{l}\text { Wana Sour Gummies } \\
\text { (Wana Brands, } \\
\text { Boulder, CO, USA) }\end{array}$ & $\begin{array}{l}15 \mathrm{kcal} \text { per serving }(\text { Fat } 0 \mathrm{~g}, \\
\text { Total carbohydrate } 4 \mathrm{~g}, \\
\text { Protein } 0 \mathrm{~g} \text { ) }\end{array}$ & $\begin{array}{l}\text { Organic Sugar, Organic Tapioca Syrup, Pectin } \\
\text { (Pectin, Potassium Sodium Tartrate, } \\
\text { Polyphosphate, Sucrose), Citric Acid, Natural } \\
\text { Flavoring and Coloring, Sodium Citrate, } \\
\text { Marijuana Concentrate, and Botanical Terpenes } \\
\text { for Flavor. }\end{array}$ \\
\hline $\begin{array}{l}\text { Welch's Fruit Snacks } \\
\text { (Park Ridge, NJ, } \\
\text { USA)* }\end{array}$ & $\begin{array}{l}15 \text { kcal per serving (Fat } 0 \mathrm{~g}, \\
\text { Carbohydrate } 2 \mathrm{~g} \text {, Sugar } 3 \\
\mathrm{~g}, \text { Protein } 0 \mathrm{~g} \text { ) }\end{array}$ & $\begin{array}{l}\text { Fruit puree (grape, peach, orange, strawberry, } \\
\text { and raspberry), corn syrup, sugar, modified corn } \\
\text { starch, gelatin, concord grape juice from } \\
\text { concentrate, citric acid, lactic acid, natural and } \\
\text { artificial flavors, ascorbic acid (vitamin C), } \\
\text { alpha tocopherol acetate (vitamin E), vitamin A } \\
\text { palmitate, sodium citrate, coconut oil, carnauba } \\
\text { wax, annatto (color), turmeric (color), red 40, } \\
\text { and blue } 1 .\end{array}$ \\
\hline
\end{tabular}

All self-administered doses of edible marijuana products contained $10 \mathrm{mg}$ THC.

*Marijuana-free control product.

MCT: Medium chain triglycerides 
Limit of Quantitation $=0.05 \mathrm{ng} / \mathrm{mL}$

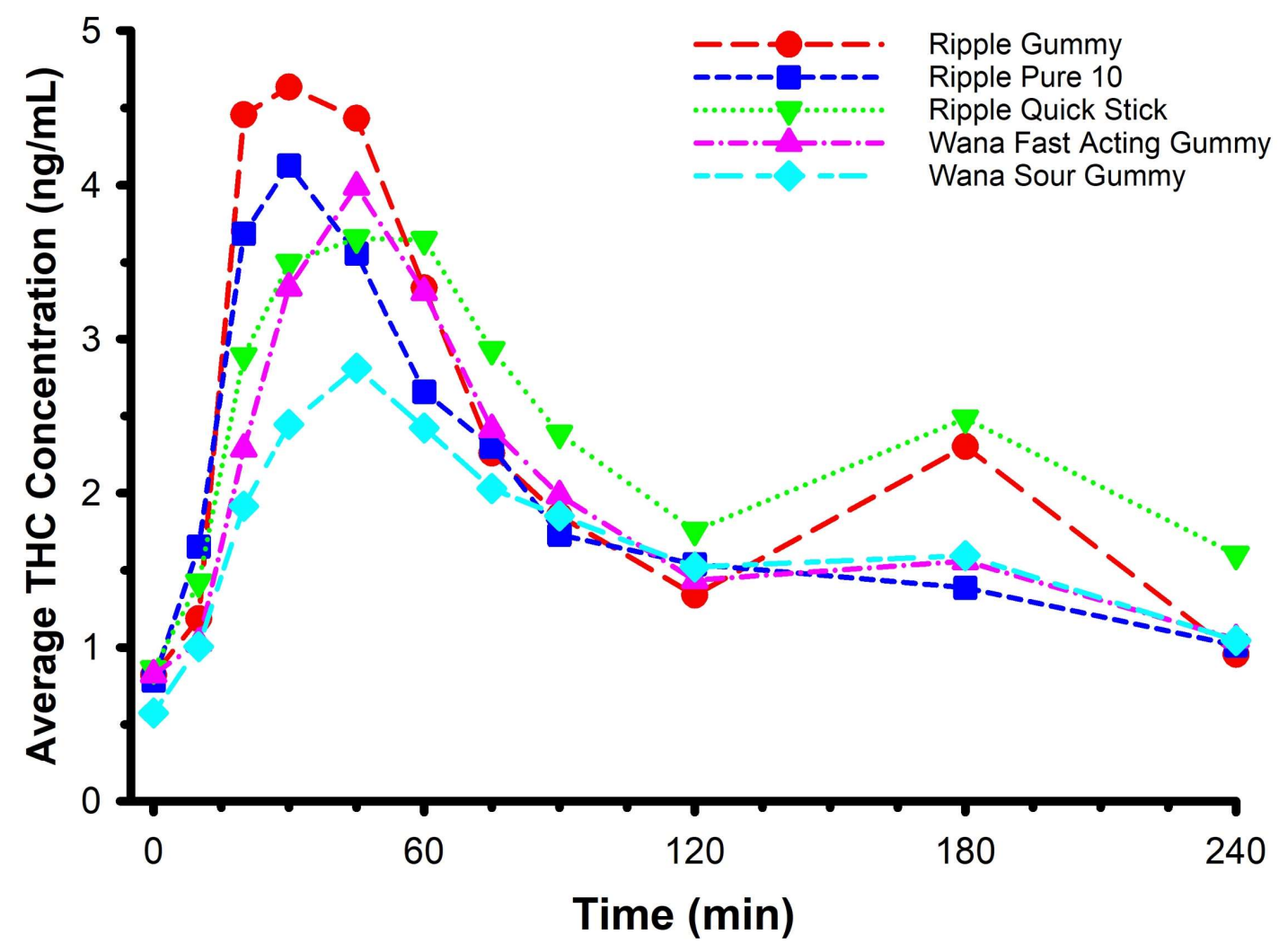

Figure 2. Mean circulating concentrations of THC following ingestion of commercially available edible marijuana (10 $\mathrm{mg}$ of THC). There was a product $\mathrm{x}$ time interaction $(P=0.019)$. Post-hoc analysis revealed circulating THC concentration was greater in Ripple Blood Orange Gummies vs. Wana Fast Acting Gummies $(\mathrm{P}=0.003)$ and Wana Sour Gummies $(P<0.001)$ at 20 minutes, and greater in Ripple Blood Orange Gummies vs. Wana Sour Gummies $(P=0.002)$, and Ripple Pure $10 v s$. Wana Sour Gummies $(P=0.038)$ at 30 minutes. Error bars have been omitted for clarity. 
Limit of Quantitation $=0.05 \mathrm{ng} / \mathrm{mL}$

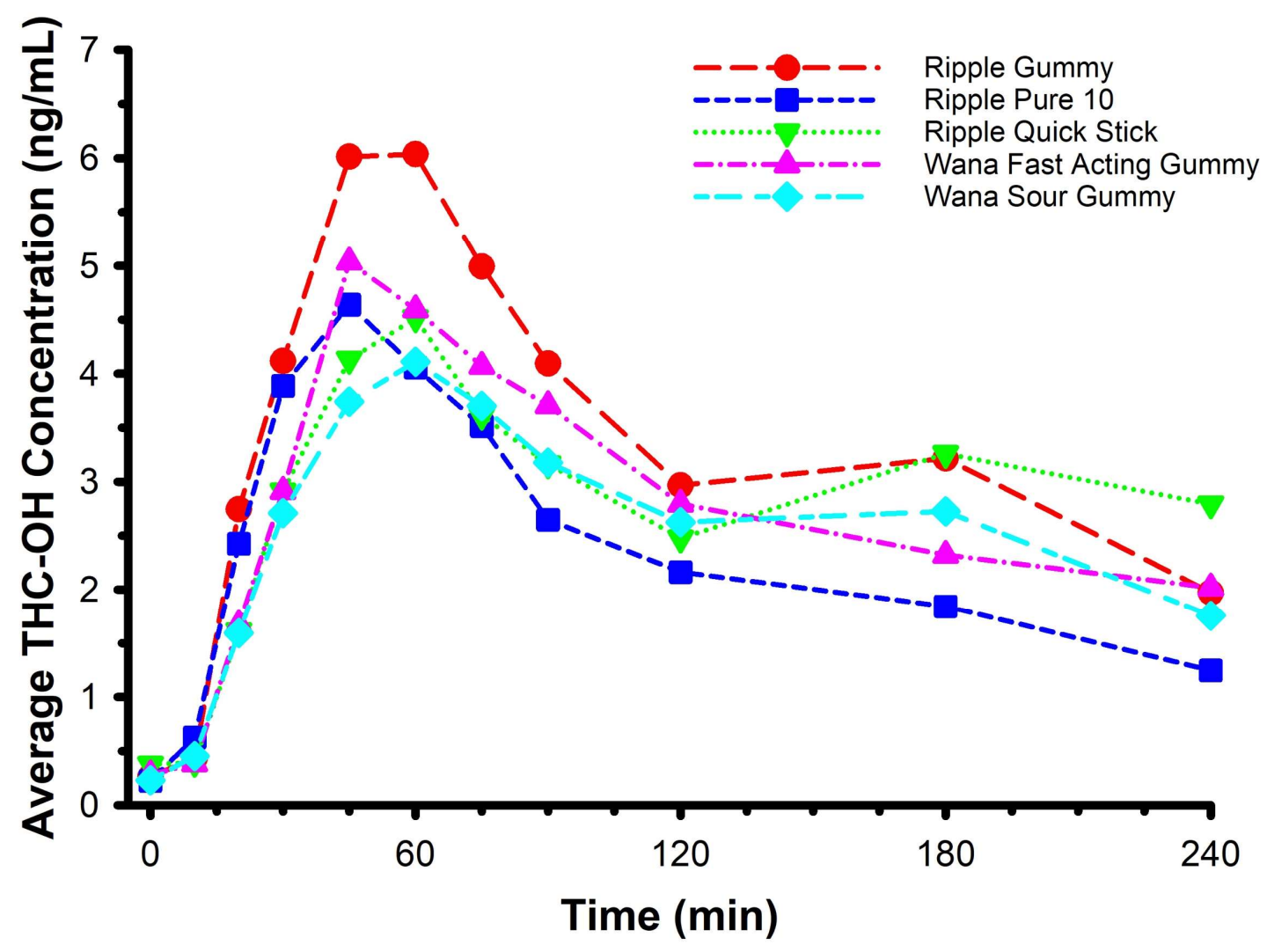

Figure 3. Mean circulating concentrations of THC-OH following ingestion of commercially available edible marijuana ( $10 \mathrm{mg}$ of THC). There were no product $\mathrm{x}$ time interactions $(P=0.415)$. Error bars have been omitted for clarity. 
Limit of Quantitation $=0.2 \mathrm{ng} / \mathrm{mL}$

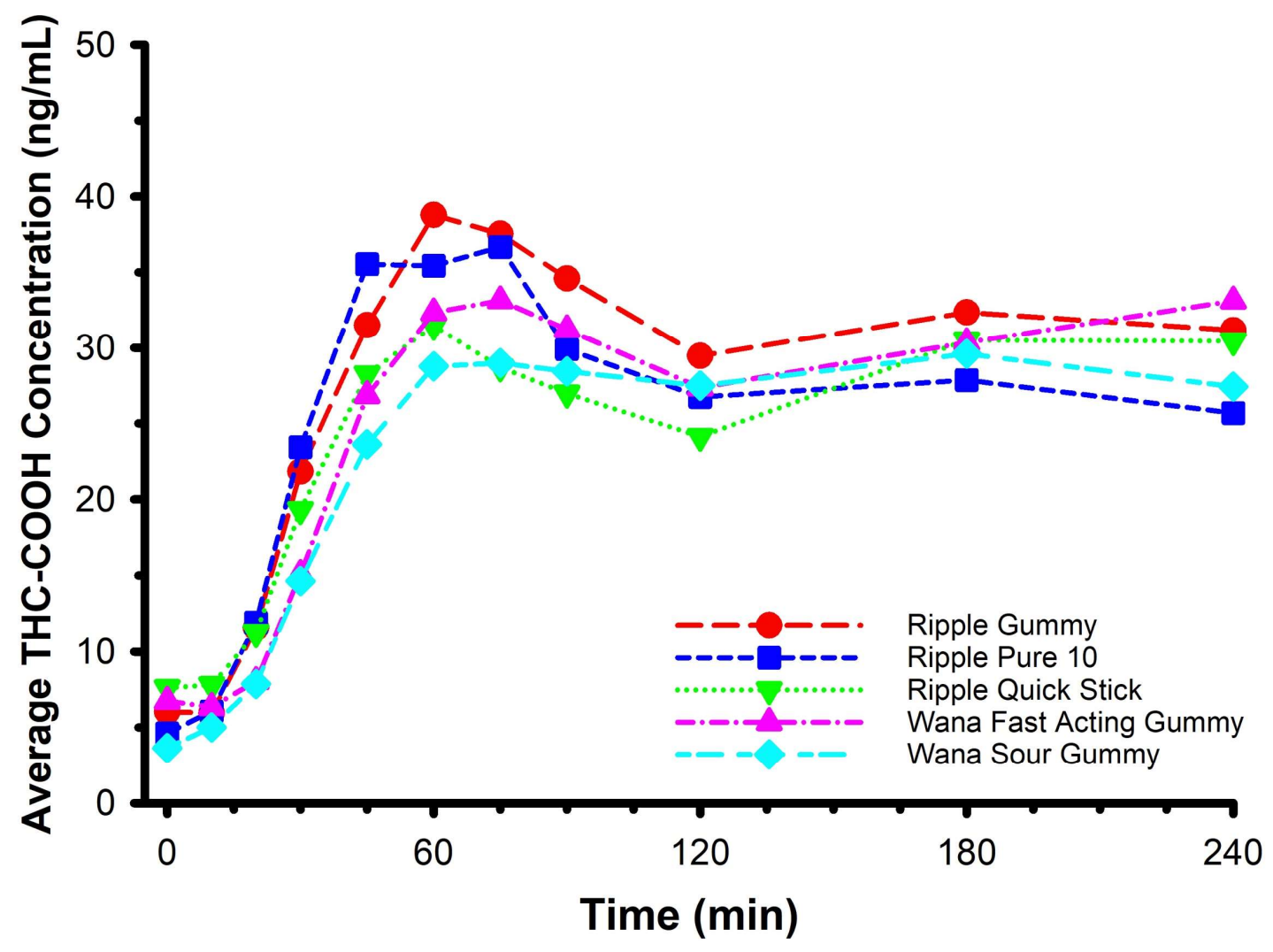

Figure 4. Mean circulating concentrations of THC-COOH following ingestion of commercially available edible marijuana ( $10 \mathrm{mg}$ of THC). There were no product $\mathrm{x}$ time interactions $(P=0.485)$. Error bars have been omitted for clarity.

Pharmacokinetic parameters for THC, THC-OH and THC-COOH are displayed in Tables 3,4 , and 5 , respectively. None of the comparisons between edible products yielded appreciable differences for any of the pharmacokinetic parameters (all $P>0.06$ ). Metabolite-to-parent ratios for $\mathrm{C}_{\max }$ and $\mathrm{AUC}_{0-240}$ are presented in Table 6. There were no appreciable differences (all $P>0.13$ ) for any of the comparisons. 
Table 3. Pharmacokinetic parameters for THC

\begin{tabular}{|c|c|c|c|c|c|c|c|c|}
\hline Product & & $\begin{array}{c}T_{\max } \\
(\min ) \\
\end{array}$ & $\begin{array}{c}\mathrm{C}_{\max } \\
(\mathrm{ng} / \mathrm{mL}) \\
\end{array}$ & $\begin{array}{c}\mathrm{AUC}_{0-240} \\
\left(\mathrm{~min}^{*} \mathrm{ng} / \mathrm{mL}\right)\end{array}$ & $\begin{array}{c}\mathbf{V}_{\mathrm{d}} \\
(\mathrm{mL})\end{array}$ & $\begin{array}{l}\mathrm{CL} / \mathbf{F}_{0-240} \\
(\mathrm{~mL} / \mathrm{min})\end{array}$ & $\begin{array}{c}k_{\mathrm{e}} \\
(\mathbf{L} / \mathbf{m i n}) \\
\end{array}$ & $\begin{array}{c}\mathbf{t}_{1 / 2} \\
(\mathrm{~min})\end{array}$ \\
\hline \multirow{4}{*}{ Ripple Gummies } & $\mathbf{n}$ & 7 & 7 & 7 & 7 & 7 & 7 & 7 \\
\hline & Mean & 35.7 & 5.54 & 533 & 4534900 & 19313 & 0.005 & 268.3 \\
\hline & SD & 12.1 & 3.10 & 286 & 4406250 & 20443 & 0.003 & 267.0 \\
\hline & Median & 45.0 & 5.22 & 463 & 2979599 & 14131 & 0.00 & 152.7 \\
\hline \multirow{4}{*}{ Ripple Pure 10} & $\mathbf{n}$ & 7 & 7 & 7 & 6 & 6 & 6 & 6 \\
\hline & Mean & 40.7 & 4.31 & 447 & 4397542 & 23966 & 0.005 & 152.4 \\
\hline & SD & 11.3 & 3.01 & 301 & 2282851 & 17028 & 0.002 & 47.1 \\
\hline & Median & 45.0 & 2.37 & 271 & 4531448 & 22193 & 0.000 & 148.6 \\
\hline \multirow{4}{*}{ Ripple Quick Sticks } & $\mathbf{n}$ & 7 & 7 & 7 & 5 & 5 & 5 & 5 \\
\hline & Mean & 90.7 & 4.56 & 570 & 2648627 & 11844 & 0.006 & 215.5 \\
\hline & SD & 84.6 & 1.80 & 268 & 1272398 & 5691 & 0.004 & 175.0 \\
\hline & Median & 60.0 & 5.17 & 632 & 2369956 & 12915 & 0.000 & 206.3 \\
\hline \multirow{3}{*}{ Wana Fast Acting Gummies } & $\mathbf{n}$ & 7 & 7 & 7 & 6 & 6 & 6 & 6 \\
\hline & Mean & 51.4 & 4.39 & 455 & 4989024 & 19431 & 0.005 & 158.8 \\
\hline & SD & 31.1 & 2.91 & 248 & 4898405 & 14590 & 0.002 & 75.5 \\
\hline \multirow{6}{*}{ Wana Sour Gummies } & Median & 45.0 & 4.29 & 421 & 2401279 & 14491 & 0.010 & 133.5 \\
\hline & $\mathbf{n}$ & 7 & 7 & 7 & 6 & 6 & 6 & 6 \\
\hline & Mean & 62.1 & 3.22 & 406 & 3960415 & 16420 & 0.004 & 180.0 \\
\hline & SD & 53.0 & 2.04 & 296 & 1463937 & 7526 & 0.001 & 68.3 \\
\hline & Median & 45.0 & 2.57 & 305 & 4462147 & 15837 & 0.000 & 165.5 \\
\hline & $P$-Value & 0.548 & 0.110 & 0.210 & 0.468 & 0.446 & 0.697 & 0.684 \\
\hline
\end{tabular}

$\mathrm{T}_{\max }$ : the time to maximum concentration. $\mathrm{C}_{\max }$ : the maximum concentration. $\mathrm{AUC}_{0-240}$ : the area under the curve representing total $\mathrm{THC}$ exposure between time 0 and end of data collection. $\mathrm{V}_{\mathrm{d}}$ : the volume of distribution, an estimate of the degree to which THC is distributed in the body tissue vs. the plasma. $\mathrm{CL} / \mathrm{F}_{0-240}$ : the apparent total clearance of the THC from plasma after oral administration. $\mathrm{K}_{\mathrm{e}}$ : the rate at which the THC is removed from the body. $\mathrm{t}^{1} / 2$ : the amount of time it takes to decrease the circulating concentration to half of its initial value. All product servings contained $10 \mathrm{mg}$ of THC. 
Table 4. Pharmacokinetic parameters for THC-OH

\begin{tabular}{|c|c|c|c|c|c|c|c|c|}
\hline Product & & $\begin{array}{c}T_{\max } \\
(\min ) \\
\end{array}$ & $\begin{array}{c}\mathrm{C}_{\max } \\
(\mathrm{ng} / \mathrm{mL})\end{array}$ & $\begin{array}{c}\mathrm{AUC}_{0-240} \\
\left(\mathrm{~min}^{*} \mathrm{ng} / \mathrm{mL}\right)\end{array}$ & $\begin{array}{c}\mathbf{V}_{\mathrm{d}} \\
(\mathrm{mL})\end{array}$ & $\begin{array}{l}\mathrm{CL} / \mathbf{F}_{0-240} \\
(\mathrm{~mL} / \mathrm{min})\end{array}$ & $\begin{array}{c}k_{\mathrm{e}} \\
(\mathrm{L} / \mathrm{min}) \\
\end{array}$ & $\begin{array}{c}\mathbf{t}_{1 / 2} \\
(\mathrm{~min})\end{array}$ \\
\hline \multirow{4}{*}{ Ripple Gummies } & $\mathbf{n}$ & 7 & 7 & 7 & 7 & 7 & 7 & 7 \\
\hline & Mean & 55.7 & 6.60 & 816 & 2993411 & 7138 & 0.005 & 512.8 \\
\hline & SD & 16.7 & 3.42 & 361 & 3760404 & 2809 & 0.002 & 989.6 \\
\hline & Median & 45.0 & 7.97 & 950 & 1284652 & 7100 & 0.000 & 149.3 \\
\hline \multirow{4}{*}{ Ripple Pure 10} & $\mathbf{n}$ & 7 & 7 & 7 & 7 & 7 & 7 & 7 \\
\hline & Mean & 53.6 & 5.05 & 560 & 3628286 & 17124 & 0.005 & 159.4 \\
\hline & SD & 17.0 & 4.20 & 359 & 2117850 & 13390 & 0.001 & 49.0 \\
\hline & Median & 45.0 & 3.32 & 447 & 3804011 & 11432 & 0.000 & 145.8 \\
\hline \multirow{4}{*}{ Ripple Quick Sticks } & $\mathbf{n}$ & 7 & 7 & 7 & 5 & 5 & 5 & 5 \\
\hline & Mean & 100.7 & 5.33 & 700 & 3036162 & 8389 & 0.003 & 403.7 \\
\hline & SD & 77.3 & 2.71 & 381 & 1634370 & 6850 & 0.003 & 335.4 \\
\hline & Median & 60.0 & 4.62 & 747 & 3076976 & 8413 & 0.000 & 267.9 \\
\hline \multirow{3}{*}{ Wana Fast Acting Gummies } & $\mathbf{n}$ & 7 & 7 & 7 & 5 & 5 & 5 & 5 \\
\hline & Mean & 83.6 & 5.40 & 669 & 1773924 & 6703 & 0.005 & 213.1 \\
\hline & SD & 49.6 & 3.71 & 361 & 783269 & 2218 & 0.002 & 154.4 \\
\hline \multirow{6}{*}{ Wana Sour Gummies } & Median & 60.0 & 4.83 & 753 & 1633620 & 6014 & 0.000 & 138.8 \\
\hline & $\mathbf{n}$ & 7 & 7 & 7 & 6 & 6 & 6 & 6 \\
\hline & Mean & 72.9 & 4.45 & 626 & 2141277 & 8860 & 0.005 & 234.0 \\
\hline & SD & 48.6 & 2.25 & 310 & 956697 & 5405 & 0.005 & 199.8 \\
\hline & Median & 60.0 & 4.36 & 544 & 1811579 & 7708 & 0.000 & 189.1 \\
\hline & $P$-Value & 0.369 & 0.390 & 0.065 & 0.758 & 0.169 & 0.975 & 0.778 \\
\hline
\end{tabular}

$\mathrm{T}_{\max }$ : the time to maximum concentration. $\mathrm{C}_{\max }$ : the maximum concentration. $\mathrm{AUC}_{0-240}$ : the area under the curve representing total THC-OH exposure between time 0 and end of data collection. $\mathrm{V}_{\mathrm{d}}$ : the volume of distribution, an estimate of the degree to which THC-OH is distributed in the body tissue $v s$. the plasma. $\mathrm{CL} / \mathrm{F}_{0-240}$ : the apparent total clearance of the THC-OH from plasma after oral administration. $\mathrm{K}_{\mathrm{e}}$ : the rate at which the THC-OH is removed from the body. $t^{1} / 2$ : the amount of time it takes to decrease the circulating concentration to half of its initial value. All product servings contained $10 \mathrm{mg}$ of THC. 
Table 5. Pharmacokinetic parameters for THC-COOH

\begin{tabular}{|c|c|c|c|c|c|c|c|c|}
\hline Product & & $\begin{array}{c}T_{\max } \\
(\min ) \\
\end{array}$ & $\begin{array}{c}\mathrm{C}_{\max } \\
(\mathrm{ng} / \mathrm{mL})\end{array}$ & $\begin{array}{c}\mathrm{AUC}_{0-240} \\
\left(\mathrm{~min}^{*} \mathrm{ng} / \mathbf{m L}\right)\end{array}$ & $\begin{array}{c}V_{d} \\
(m L)\end{array}$ & $\begin{array}{l}\mathrm{CL} / \mathbf{F}_{0-240} \\
(\mathrm{~mL} / \mathrm{min})\end{array}$ & $\begin{array}{c}k_{\mathrm{e}} \\
(\mathbf{L} / \mathbf{m i n}) \\
\end{array}$ & $\begin{array}{c}\mathbf{t}_{1 / 2} \\
(\mathrm{~min})\end{array}$ \\
\hline \multirow{4}{*}{ Ripple Gummies } & $\mathbf{n}$ & 7 & 7 & 7 & 4 & 4 & 4 & 4 \\
\hline & Mean & 105.0 & 44.01 & 7047 & 266200 & 484 & 0.002 & 365.3 \\
\hline & SD & 75.0 & 21.32 & 3264 & 140158 & 147 & 0.000 & 97.3 \\
\hline & Median & 60.0 & 34.28 & 6251 & 241269 & 514 & 0.000 & 325.7 \\
\hline \multirow{4}{*}{ Ripple Pure 10} & $\mathbf{n}$ & 7 & 7 & 7 & 6 & 6 & 6 & 6 \\
\hline & Mean & 87.9 & 40.24 & 6311 & 360519 & 569 & 0.001 & 846.3 \\
\hline & SD & 67.9 & 19.44 & 3137 & 194482 & 420 & 0.001 & 986.7 \\
\hline & Median & 60.0 & 34.15 & 5154 & 299004 & 568 & 0.000 & 487.8 \\
\hline \multirow{4}{*}{ Ripple Quick Sticks } & $\mathbf{n}$ & 7 & 7 & 7 & 3 & 3 & 3 & 3 \\
\hline & Mean & 130.7 & 42.25 & 6195 & 288446 & 802 & 0.003 & 272.2 \\
\hline & SD & 86.0 & 22.51 & 3667 & 28675 & 344 & 0.001 & 80.7 \\
\hline & Median & 75.0 & 35.63 & 5870 & 301043 & 674 & 0.000 & 309.4 \\
\hline \multirow{3}{*}{ Wana Fast Acting Gummies } & $\mathbf{n}$ & 7 & 7 & 7 & 3 & 3 & 3 & 3 \\
\hline & Mean & 145.7 & 39.36 & 6467 & 312251 & 363 & 0.001 & 611.4 \\
\hline & SD & 84.3 & 15.12 & 2798 & 201295 & 247 & 0.000 & 73.8 \\
\hline \multirow{6}{*}{ Wana Sour Gummies } & Median & 180.0 & 41.04 & 6203 & 208977 & 262 & 0.000 & 585.7 \\
\hline & $\mathbf{n}$ & 7 & 7 & 7 & 2 & 2 & 2 & 2 \\
\hline & Mean & 145.7 & 35.78 & 6009 & 297051 & 758 & 0.003 & 677.6 \\
\hline & SD & 68.6 & 18.89 & 3324 & 81970 & 789 & 0.003 & 780.3 \\
\hline & Median & 180.0 & 29.09 & 5119 & 297051 & 758 & 0.000 & 677.6 \\
\hline & $P$-Value & 0.514 & 0.746 & 0.642 & 0.134 & 0.680 & 0.107 & 0.860 \\
\hline
\end{tabular}

$\mathrm{T}_{\max }$ : the time to maximum concentration. $\mathrm{C}_{\max }$ : the maximum concentration. $\mathrm{AUC}_{0-240}$ : the area under the curve representing total THC-COOH exposure between time 0 and end of data collection. $\mathrm{V}_{\mathrm{d}}$ : the volume of distribution, an estimate of the degree to which THC-COOH is distributed in the body tissue $v s$. the plasma. $\mathrm{CL} / \mathrm{F}_{0-240}$ : the apparent total clearance of the $\mathrm{THC}-\mathrm{COOH}$ from plasma after oral administration. $\mathrm{K}_{\mathrm{e}}$ : the rate at which the THC-COOH is removed from the body. $\mathrm{t}^{1} / 2$ : the amount of time it takes to decrease the circulating concentration to half of its initial value. All product servings contained $10 \mathrm{mg}$ of THC. 
Table 6. Metabolite-to-parent ratios for $\mathrm{C}_{\max }$ and $\mathrm{AUC}_{0-240}$

\begin{tabular}{|c|c|c|c|c|c|}
\hline \multirow{2}{*}{ Product } & \multirow[b]{3}{*}{ n } & \multicolumn{2}{|c|}{ THC-OH/THC } & \multicolumn{2}{|c|}{ THC-COOH/THC } \\
\hline & & $\mathbf{C}_{\max }$ & AUC0-240 & $C_{\max }$ & AUC $0-240$ \\
\hline & & 7 & 7 & 7 & 7 \\
\hline Ripple & Mean & 1.22 & 1.64 & 10.54 & 17.10 \\
\hline \multirow[t]{3}{*}{ Gummies } & SD & 0.26 & 0.45 & 7.14 & 12.49 \\
\hline & Median & 1.26 & 1.51 & 6.53 & 11.12 \\
\hline & $\mathbf{n}$ & 7 & 7 & 7 & 7 \\
\hline Ripple Pure & Mean & 1.11 & 1.35 & 11.46 & 16.06 \\
\hline \multirow[t]{2}{*}{10} & SD & 0.24 & 0.53 & 5.31 & 5.53 \\
\hline & Median & 1.02 & 1.21 & 10.52 & 14.55 \\
\hline \multirow{4}{*}{$\begin{array}{l}\text { Ripple } \\
\text { Quick } \\
\text { Sticks }\end{array}$} & $\mathbf{n}$ & 7 & 7 & 7 & 7 \\
\hline & Mean & 1.28 & 2.06 & 10.84 & 11.76 \\
\hline & SD & 0.58 & 2.35 & 6.63 & 4.58 \\
\hline & Median & 1.21 & 1.33 & 8.83 & 10.81 \\
\hline \multirow{4}{*}{$\begin{array}{l}\text { Wana Fast } \\
\text { Acting } \\
\text { Gummies }\end{array}$} & $\mathbf{n}$ & 7 & 7 & 7 & 7 \\
\hline & Mean & 1.27 & 1.53 & 13.24 & 17.02 \\
\hline & SD & 0.29 & 0.44 & 7.99 & 7.24 \\
\hline & Median & 1.17 & 1.57 & 11.52 & 18.05 \\
\hline \multirow{5}{*}{$\begin{array}{l}\text { Wana Sour } \\
\text { Gummies }\end{array}$} & $\mathbf{n}$ & 7 & 7 & 7 & 7 \\
\hline & Mean & 1.44 & 1.68 & 12.64 & 16.43 \\
\hline & SD & 0.25 & 0.51 & 5.19 & 4.32 \\
\hline & Median & 1.46 & 1.82 & 11.37 & 16.77 \\
\hline & $P$-Value & 0.344 & 0.195 & 0.772 & 0.137 \\
\hline
\end{tabular}

Body Composition

Correlations between parameters of body composition and pharmacokinetics are presented in Table 7. While significant relations were identified between body composition and pharmacokinetic parameters for some products, none of these body composition characteristics were consistently related to pharmacokinetic parameters across all five of the products.

Table 7. Pearson correlations between parameters of body composition and THC pharmacokinetics

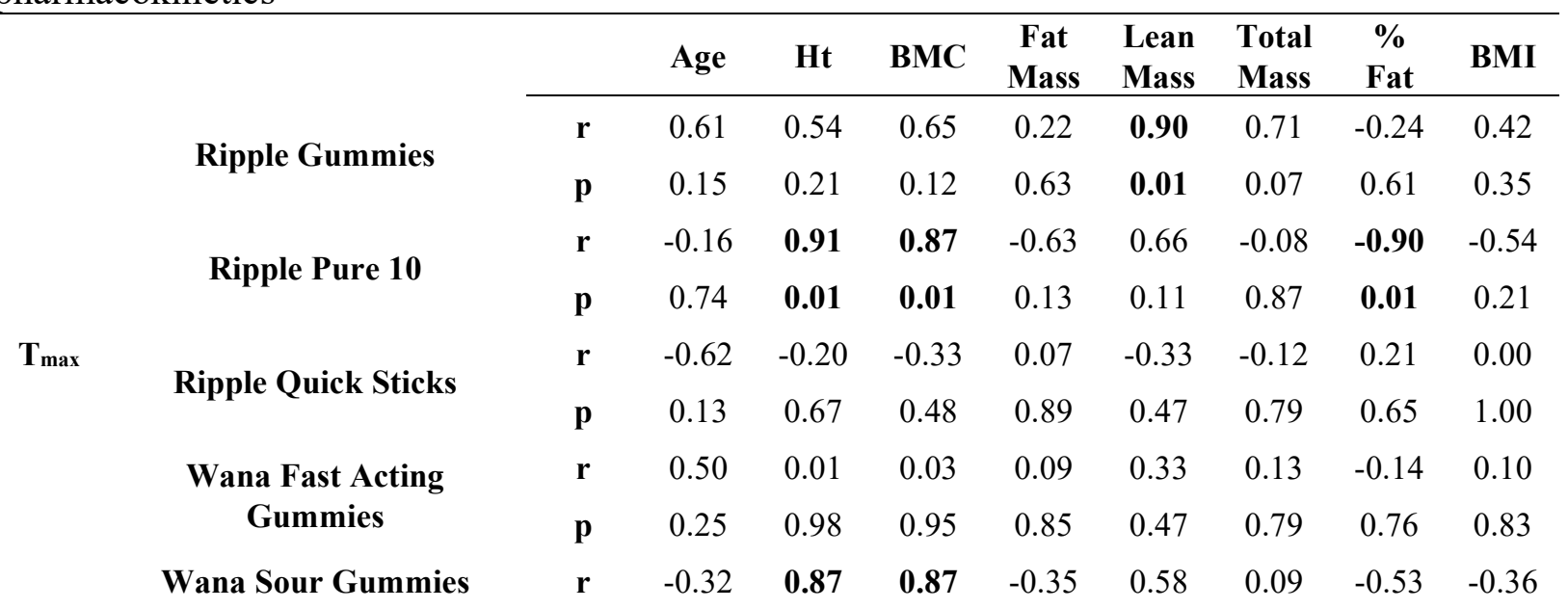




\begin{tabular}{|c|c|c|c|c|c|c|c|c|c|c|}
\hline & & $\mathbf{p}$ & 0.47 & 0.01 & 0.01 & 0.45 & 0.17 & 0.85 & 0.22 & 0.43 \\
\hline \multirow{10}{*}{$\mathrm{C}_{\max }$} & \multirow{2}{*}{ Ripple Gummies } & $\mathbf{r}$ & -0.24 & -0.68 & -0.77 & 0.30 & -0.80 & -0.25 & 0.58 & 0.10 \\
\hline & & $\mathbf{p}$ & 0.61 & 0.09 & 0.04 & 0.51 & $\mathbf{0 . 0 3}$ & 0.58 & 0.17 & 0.82 \\
\hline & \multirow{2}{*}{ Ripple Pure 10} & $\mathbf{r}$ & -0.21 & -0.48 & -0.60 & 0.35 & -0.62 & -0.12 & 0.58 & 0.13 \\
\hline & & $\mathbf{p}$ & 0.65 & 0.28 & 0.15 & 0.44 & 0.14 & 0.80 & 0.17 & 0.79 \\
\hline & \multirow{2}{*}{ Ripple Quick Sticks } & $\mathbf{r}$ & -0.21 & 0.03 & -0.04 & -0.19 & -0.31 & -0.34 & -0.10 & -0.36 \\
\hline & & $\mathbf{p}$ & 0.65 & 0.95 & 0.93 & 0.68 & 0.50 & 0.45 & 0.84 & 0.43 \\
\hline & \multirow{2}{*}{$\begin{array}{l}\text { Wana Fast Acting } \\
\text { Gummies }\end{array}$} & $\mathbf{r}$ & -0.07 & -0.36 & -0.46 & 0.29 & -0.38 & -0.00 & 0.31 & 0.18 \\
\hline & & $\mathbf{p}$ & 0.89 & 0.43 & 0.30 & 0.53 & 0.40 & 0.99 & 0.51 & 0.69 \\
\hline & \multirow{2}{*}{ Wana Sour Gummies } & $\mathbf{r}$ & 0.21 & -0.63 & -0.66 & 0.73 & -0.42 & 0.29 & 0.84 & 0.60 \\
\hline & & $\mathbf{p}$ & 0.65 & 0.13 & 0.11 & 0.06 & 0.34 & 0.53 & 0.02 & 0.16 \\
\hline \multirow{10}{*}{$\begin{array}{c}\text { AUC } \\
0-240\end{array}$} & \multirow{2}{*}{ Ripple Gummies } & $\mathbf{r}$ & 0.05 & -0.63 & -0.75 & 0.65 & -0.49 & 0.20 & 0.74 & 0.52 \\
\hline & & $\mathbf{p}$ & 0.92 & 0.13 & 0.05 & 0.12 & 0.27 & 0.67 & 0.06 & 0.23 \\
\hline & \multirow{2}{*}{ Ripple Pure 10} & $\mathbf{r}$ & -0.12 & -0.34 & -0.54 & 0.56 & -0.32 & 0.23 & 0.59 & 0.40 \\
\hline & & $\mathbf{p}$ & 0.80 & 0.46 & 0.21 & 0.19 & 0.49 & 0.62 & 0.17 & 0.38 \\
\hline & \multirow{2}{*}{ Ripple Quick Sticks } & $\mathbf{r}$ & -0.17 & -0.06 & -0.23 & 0.03 & -0.25 & -0.13 & 0.04 & -0.10 \\
\hline & & $\mathbf{p}$ & 0.71 & 0.89 & 0.62 & 0.95 & 0.58 & 0.78 & 0.93 & 0.83 \\
\hline & \multirow{2}{*}{$\begin{array}{l}\text { Wana Fast Acting } \\
\text { Gummies }\end{array}$} & $\mathbf{r}$ & 0.07 & -0.43 & -0.52 & 0.39 & -0.34 & 0.10 & 0.38 & 0.32 \\
\hline & & $\mathbf{p}$ & 0.88 & 0.34 & 0.24 & 0.39 & 0.46 & 0.83 & 0.40 & 0.49 \\
\hline & \multirow{2}{*}{ Wana Sour Gummies } & $\mathbf{r}$ & 0.35 & -0.47 & -0.52 & 0.89 & -0.13 & 0.59 & 0.83 & 0.82 \\
\hline & & $\mathbf{p}$ & 0.44 & 0.29 & 0.23 & 0.01 & 0.79 & 0.16 & 0.02 & 0.02 \\
\hline
\end{tabular}

$n=7$ for all cells. Ht: Height. BMC: Bone Mineral Content. BMI: Body Mass Index. AUC ${ }_{0-240}$ : Area under the concentration curve between time 0 and 240-minutes (4-hours). Statistically significant correlations have been bolded for clarity.

\section{Oral Glucose Tolerance}

Mean circulating glucose concentrations across the six conditions (including marijuanafree control) during an oral glucose tolerance test (OGTT) are displayed in Figure 5. 75g of glucose was imbibed as a beverage 30-minutes after ingestion of marijuana (or control). Fasting glucose was not different across laboratory visits $(P=0.40)$. Circulating glucose was not different from fasting glucose 30 -minutes after product ingestion $(\mathrm{P}=0.88)$, implying that the carbohydrate content of the edible products was too low to evoke an appreciable hyperglycemic response. Compared with marijuana-free control, none of the edible marijuana products influenced circulating glucose throughout each of the trials (product x time interaction $P=0.98$ ). Consistent with this observation, none of the edible marijuana products influenced other indices of the glucose response, including 2-hour $\operatorname{AUC}(P=0.98$; data not shown $)$ and 3.5-hour AUC $(P=0.92$; data not shown). 


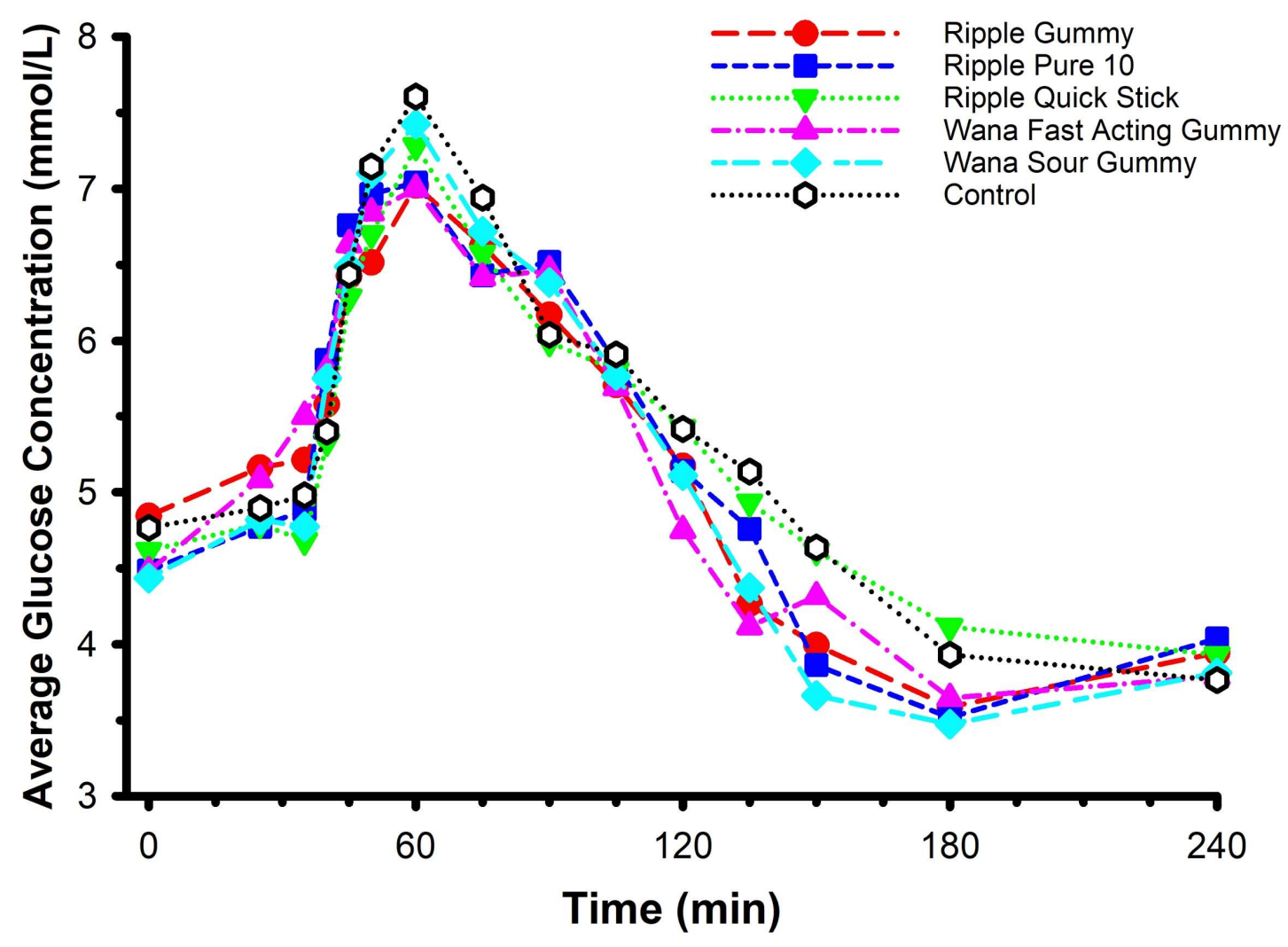

Figure 5. Mean circulating glucose concentrations following ingestion of commercially available edible marijuana (10 $\mathrm{mg}$ of THC) and one marijuana-free control product. $75 \mathrm{~g}$ of glucose was ingested at 30-minutes. Fasting glucose was not different across study sessions $(P=0.40)$. Circulating glucose was not different from fasting glucose 30 -minutes after product ingestion $(\mathrm{P}=0.88)$. Compared with placebo, none of the edible marijuana products influenced circulating glucose throughout each of the trials (product $\mathrm{x}$ time interaction $P=0.98$ ). Error bars have been omitted for clarity.

An absence of difference in circulating glucose does not necessarily imply an absence of difference in glucose regulation. Accordingly, circulating insulin concentration was determined for two of the products, Ripple Blood Orange Gummies and Ripple Pure 10, and compared against the marijuana-free control (Figure 6). These two specific products were selected on account of the higher plasma THC concentrations evoked by their ingestion (Figure 2). Consistent with the glucose data, there were no differences in circulating insulin between products (product x time interaction $P=0.74)$ and 2-hour AUC $(P=0.70)$ nor were there any differences in glucose/insulin derived indices of glucose regulation, including HOMA-IR $(P=0.30$; data not shown) and the Matsuda Index ( $P=0.40$; data not shown). 


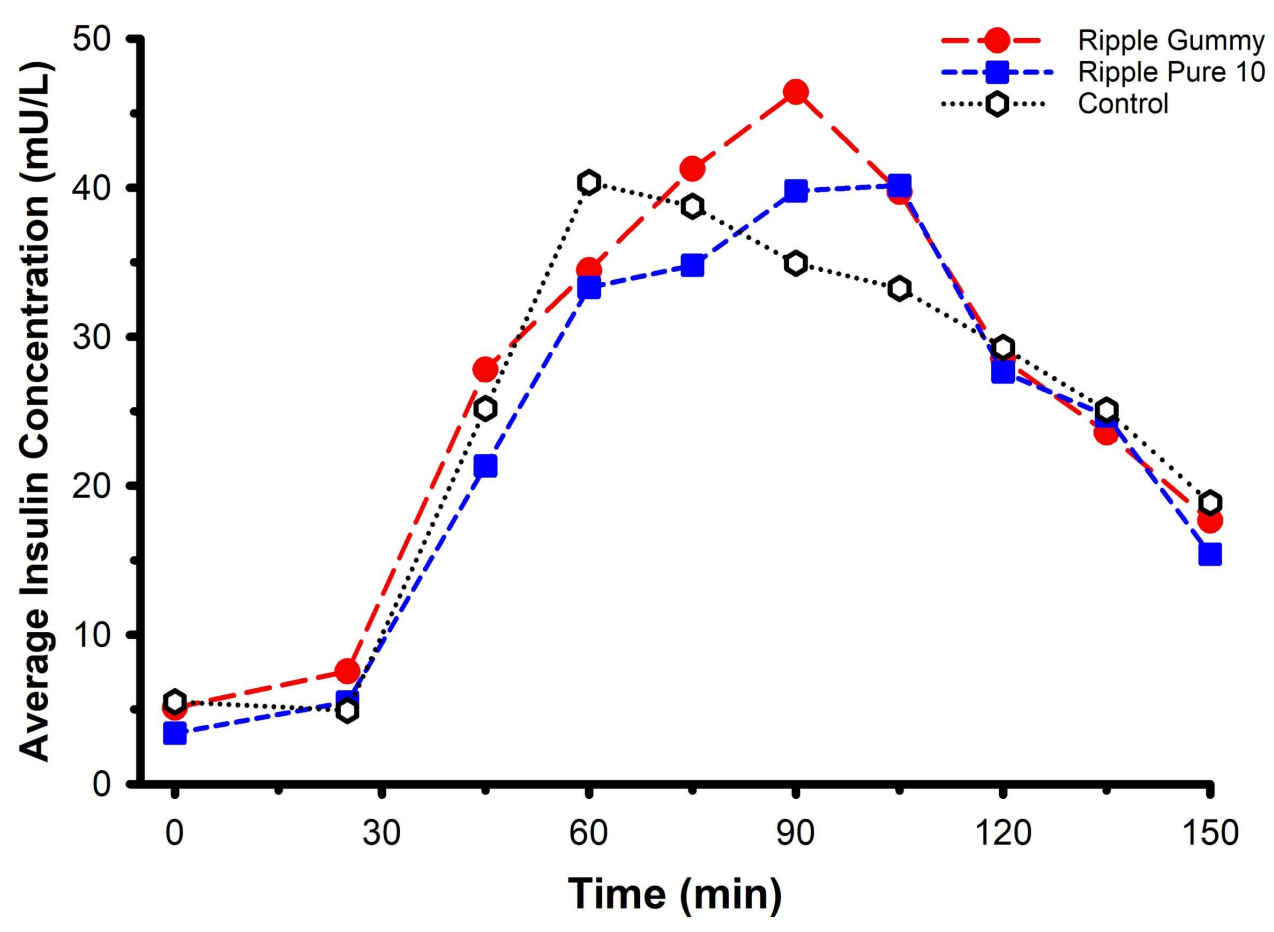

Figure 6. Mean circulating insulin concentrations following ingestion of two commercially available edible marijuana (10 mg of THC) and one marijuana-free control product. $75 \mathrm{~g}$ of glucose was ingested at 30-minutes. There were no differences in circulating insulin between products (product x time interaction $P=0.74$ ). Error bars have been omitted for clarity.

\section{DISCUSSION}

The aims of the current study were: (1) To describe the pharmacokinetics of circulating THC, two of its metabolites (THC-OH and THC-COOH), and the metabolite to parent ratio, following ingestion of five commercially available edible marijuana products. (2) To compare the pharmacokinetics of five different commercially available edible marijuana products. (3) To determine the influence of body composition on THC pharmacokinetics. (4) To explore the potential acute influence of edible marijuana on glucose regulation. Our primary findings were: (1) THC $\mathrm{T}_{\max }$ ranged between 35 and 90 minutes, and $\mathrm{THC} \mathrm{C}_{\max }$ ranged between 3.2 and 5.5 $\mathrm{ng} / \mathrm{mL}$. (2) Differences between products in plasma THC concentration during the first 20-30 minutes were detected $(P=0.019)$. There were no differences between products in the metabolite-to-parent $\mathrm{C}_{\max }$ and $\mathrm{AUC}$ ratios for $\mathrm{THC}-\mathrm{COOH}$ and $\mathrm{THC}-\mathrm{OH}$ (all $P>0.13$ ). (3) Significant relations were identified between body composition and pharmacokinetic parameters for some products, however none of these body composition characteristics were consistently related to pharmacokinetic parameters across all five of the products. (4) Compared with a control condition, edible marijuana had no effect on any of the indices of glucose regulation, including Matsuda Index, and 2.0 and 3.5-hour AUC.

Commercially available edible marijuana products are becoming increasingly popular alternatives to inhaled combusted marijuana, in part due to the perceived lower cardiopulmonary risk associated with protecting lungs from exposure to smoke. However, as with marijuana prepared for burning/smoking, considerable pharmacokinetic variability exists between edible marijuana products, even when standardized for THC content. For example, in two recent studies of cannabis-infused brownies containing 50-mg of THC, THC $\mathrm{C}_{\text {max }}$ ranged between 2.5 
$\mathrm{ng} / \mathrm{mL}$ and $4 \mathrm{ng} / \mathrm{mL}$, and $\mathrm{T}_{\max }$ between 1 and 2 hours [9,10]. In contrast, in the present study research participants self-administered commercially available edible marijuana containing only $10 \mathrm{mg}$ of THC, and $\mathrm{C}_{\max }$ ranged between 3.2 and $5.5 \mathrm{ng} / \mathrm{mL}$, while $\mathrm{T}_{\max }$ ranged between 35 and 90 minutes. Thus, several of the commercially available preparations containing only $20 \%$ of the THC content of the brownies evoked greater circulating concentrations of THC, and in a shorter period. To account for these discrepancies between studies, we have considered several potential explanations. In addition to cannabis, the brownies contained additional ingredients, including fats and sugars, that contributed to a greater caloric load compared with a single (10 $\mathrm{mg}$ THC) serving of any of the commercial edible marijuana studied in the current investigation; we conservatively estimate $100 \mathrm{vs} .0-30 \mathrm{kcal}$, respectively. It is plausible that the additional caloric load of the brownies interfered with the rate and amount of THC absorption from the gut [29]. Second, the brownies were typical/normal food supplemented with cannabis, whereas the commercial products under investigation were engineered to provide superior delivery of THC. This engineering includes the development of water-soluble THC and marijuana concentrate, and controlled addition of solubility agents, such as gum arabic and medium-chain triglycerides (MCTs), that have been shown to promote delivery and bioavailability of dietary supplements [30,31]. Third, in a separate brownie study [8], approximately $50 \mathrm{mg}$ of THC incorporated within a brownie produced a THC $\mathrm{C}_{\max }$ (measured in whole blood) of $4.7-34.8 \mathrm{ng} / \mathrm{mL}$ in frequent marijuana users ( $\geq 5$ times per week) and 3.6-22.5 ng/mL in occasional marijuana users $(\leq 3$ times per week). In the same study, THC $\mathrm{T}_{\max }$ was 1.5-3.5 hours for both frequent and occasional users. These data imply that the degree of habitual marijuana use may promote THC $\mathrm{C}_{\max }$ independent of $\mathrm{T}_{\max }$., thus when comparing across studies, data must be interpreted with caution if habitual marijuana use is not reported. In the current study, a repeated measures crossover design was employed, thus comparison within the study should not be compromised by heterozygous habitual cannabis/marijuana use.

Previously, it has been reported that parameters of oral CBD pharmacokinetics, including $\mathrm{T}_{\max }$, were associated with anthropometric variables, including fat free mass and body mass index [11]. A number of explanations were proposed, such as the positive relationship between fat free mass and blood volume [32,33], representing a greater reservoir in which to dilute circulating metabolites; greater perfusion of metabolically active tissues, thereby leading to enhanced clearance of circulating metabolites; and, the lipophilic nature of CBD. In the current study we extend these observations and arguments to consider a potential role of body composition specific to THC pharmacokinetics. To our knowledge, our data are the first to directly address this issue. While significant relations were identified between body composition and pharmacokinetic parameters for some of the edible marijuana products (Table 7), none of these body composition characteristics were consistently related to pharmacokinetic parameters across all five of the studied products. Similar to CBD, THC is thought to be lipophilic and consequently absorbed by adipose tissue. Two lines of evidence from frequent marijuana users support this claim: THC is quantifiable in fat biopsies taken 4-weeks after previous marijuana use [12], and circulating THC concentration is increased following 35-minutes of lipolysisinducing moderate intensity stationary cycle ergometer exercise [34]. Similar exercise-mediated observations have been reported in exercising rats pre-treated with THC [35], but not reproduced in a smaller follow-up study of humans with low-to-recommended BMI (range: $19-$ to- $23 \mathrm{~kg} / \mathrm{m}^{2}$ ) [36]. Our analysis revealed inconsistent correlations for absolute and/or $\%$ fat mass for $\mathrm{T}_{\max }$, $\mathrm{C}_{\max }$ and $\mathrm{AUC}_{0-240}$ for only some of the products. Although our study population was small, the range in adiposity and BMI was large, ranging from lean-to-obese. The heterozygous nature of 
the body composition data should have facilitated the identification of potentially significant correlations. While it appears likely that in vivo THC is lipophilic and absorbed by adipose tissue, adipose may not appreciably contribute to short-term edible marijuana pharmacokinetics.

The final aim of the current study was to explore the potential acute influence of edible marijuana on glucose regulation. The connection between marijuana use and the development of insulin resistance and diabetes is not clearly understood. On one hand, there exists an intuitive link: marijuana use is associated with increased appetite [37], leading to increased dietary intake, and in particular increased purchase of foods of high caloric but poor nutritional value ("junk food") [38]. If this behavior is chronic then weight (fat) gain typically ensues, and the overweight and obese states are causally tied to insulin resistance and diabetes. However, on the other hand, most of the epidemiological research suggests that marijuana use either has no effect on diabetes risk, or in many cases lowers the risk of diabetes, even when taking into account other potential confounding variables such as body composition [19-23]. The collective concluding recommendation provided by the authors of these studies was the need for randomized controlled trials to provide definitive insight. To our knowledge, aside from some preliminary work completed in the 1970's [24-26], there have been no human intervention studies to support the epidemiology. The early preliminary work involved intravenous marijuana administration and inhalation of combusted marijuana, and resulted in either impaired or unaltered acute glucose regulation. Inhalation of combustible materials typically leads to temporarily decreased oxygen transport (i.e. relative hypoxia) and increased sympathoadrenal activity, two conditions known to unfavorably modify glucose control $[39,40]$. Further, since these early studies, the THC potency of marijuana products has increased [27] and the methods of marijuana consumption have become more diverse [1], thus our goal in the present study was to update the paradigm using commercially available edible marijuana with THC doses reflective of contemporary use. The gold-standard measurement of glucose regulation and insulin sensitivity is the hyperinsulinemic euglycemic clamp technique, involving the intravenous co-administration of insulin and glucose. Unfortunately, on account of state laws and institutional regulations, marijuana is not permitted in our university clinical research facility, thus we compromised by studying glucose regulation using a modified OGTT in a field-setting. None of the five commercially available edible marijuana products influenced the acute circulating glucose response to standardized glucose ingestion $(P=0.98)$. The variability in circulating glucose across conditions was akin to desirable studies of test-re-test reliability [41]. The primary hormone involved in glucose regulation is insulin. Improvements in glucose control are not always necessarily reflected by lower circulating glucose concentrations [42]; improved glucose regulation may be reflected by lower insulin in the absence of modified glucose values. For this reason, we compared the OGTT insulin response in the control condition to the OGTT insulin response to two of the five edible marijuana products. There were no differences in circulating insulin between products, nor were there any differences in glucose/insulin derived indices of glucose regulation, including the Matsuda Index. Based on our data and in light of the epidemiological studies [19-23], we suggest that edible marijuana does not affect acute glucose regulation, but potentially may exert a favorable chronic influence via long-term physiological responses such as decreased adiposity [43], and improved gut [44] and/or liver health [45].

In summary, knowledge of pharmacokinetics associated with different commercially available edible marijuana products may prevent accidental overdose due to premature repeat dosing. THC $\mathrm{T}_{\max }$ and $\mathrm{C}_{\max }$ ranged between 35 and 90 minutes, and between 3.2 and $5.5 \mathrm{ng} / \mathrm{mL}$, respectively. Differences exist between commercial products with respect to plasma THC 
concentration during the first 20-30 minutes following ingestion. Body composition does not appear to be an acute determinant of edible marijuana pharmacokinetics. Edible marijuana does not appear to affect acute glucose regulation, but in light of epidemiological data, marijuana potentially may exert a favorable influence on long-term glucose regulation and diabetes-risk.

\section{MATERIALS AND METHODS}

The study was conducted according to the guidelines of the Declaration of Helsinki and approved by the Institutional Review Board of Colorado State University (Protocol \#20-10278H, $8^{\text {th }}$ of October 2020). This study utilized a randomized, repeated measures crossover design. All participants provided written informed consent prior to commencement of the study.

\section{Participants}

Adult men and women aged 21 or over were invited to participate. Inclusion criteria included body mass greater than $50 \mathrm{~kg}$, regular use of marijuana ( $\geq$ four times in the previous month), willingness to abstain from all products derived from Cannabis sativa L. during the four days prior to each data collection, and previous use of a Cannabis sativa L. product containing $\geq 10 \mathrm{mg}$ of THC without a significant adverse reaction. Exclusion criteria included pregnancy, breastfeeding, treatment for psychosis, bipolar disorder or schizophrenia, current or previous use of medication for treatment or prevention of diabetes, previous diagnoses of heart disease, peripheral vascular disease, high blood pressure, stroke, or heart murmur, and/or use of medication contraindicated for concurrent use with marijuana, or known to influence glycemic control.

\section{Protocol Overview}

To remain compliant with institutional and state laws pertaining to marijuana, an observational approach was employed in a manner inspired by previous reports [28]. Following screening, on six mornings, each separated by a minimum of 1-week, participants selfadministered one of five edible marijuana products or a marijuana-free control product in a randomized crossover design; each marijuana product contained $10 \mathrm{mg}$ of THC. 30-minutes following marijuana (or marijuana-free control) ingestion, participants imbibed a carbohydrate beverage containing $75 \mathrm{~g}$ of glucose. Venous blood was sampled repeatedly over 4-hours and was analyzed for circulating concentrations of $\mathrm{THC}, \mathrm{THC}-\mathrm{COOH}, \mathrm{THC}-\mathrm{OH}$, glucose, and insulin.

\section{Procedures}

Prior to study enrollment, potential participants completed a detailed electronic medical history questionnaire. Responses requiring additional query were addressed either in-person, via telephone or video conference. Body size and composition were assessed at Colorado State University using dual energy x-ray absorptiometry (DEXA; Hologic, DiscoveryW, QDR Series, Bedford, MA, USA), and a physician's digital scale and stadiometer.

The remaining data collection sessions were completed off-campus on six mornings, each separated by 1-2 weeks depending on participant schedules. The time of protocol initiation was kept constant for each participant. Every data collection was preceded by a 12-hour fast, 24-hour abstention from alcohol and exercise, and 96-hour abstention from any products derived from Cannabis sativa L., including CBD and marijuana. 
A venous catheter was introduced to an antecubital or dorsal hand vein and blood $(\sim 10$ $\mathrm{mL}$ ) was collected for analysis of baseline circulating concentrations of THC, THC-COOH, THC-OH, glucose, and insulin. Immediately following baseline blood collection, participants self-administered one of five edible marijuana products or a marijuana-free control product (described in detail in a subsequent section). 30-minutes following marijuana (or marijuana-free control) ingestion, participants imbibed a beverage consisting of $75 \mathrm{~g}$ of glucose dissolved in 250 $\mathrm{mL}$ of water (i.e. an oral glucose tolerance test (OGTT)).

Relative to marijuana ingestion (Time 0), venous blood was sampled for subsequent analysis of circulating concentrations of THC, THC-COOH, and THC-OH at minutes 10, 20, 30, $45,60,75,90,120,180$, and 240. Blood was immediately transferred into chilled tubes coated with ethylenediaminetetraacetic acid (K3 EDTA) and placed on ice for up to 30 minutes before isolation of plasma via chilled $\left(4{ }^{\circ} \mathrm{C}\right)$ centrifugation. One $\mathrm{mL}$ aliquots of plasma were then placed on ice while being transported to the research facility for storage at $-80{ }^{\circ} \mathrm{C}$ prior to subsequent analysis.

Relative to marijuana ingestion (Time 0), the carbohydrate beverage was imbibed at minute 30. Venous blood was sampled for subsequent analysis of circulating concentrations of glucose at minutes 25 (i.e. post-marijuana but pre-glucose), 35, 40, 45, 50, 60, 75, 90, 105, 120, $135,150,180$ and 240, and at minutes $25,45,75,105,135$, and 150 for subsequent analysis of plasma insulin concentration. Blood intended for glucose analysis was transferred to chilled tubes containing sodium fluoride (potassium oxalate), and then immediately placed on ice for transport to the research facility where it was evaluated, in duplicate, without delay using an automated analyzer (YSI 2900 STAT Glucose Lactate Analyzer, YSI Inc., Yellow Springs, OH, USA). Blood intended for insulin analysis was processed in an identical manner to the blood used for THC, THC-COOH, and THC-OH analysis. Plasma insulin concentration was determined in triplicate via enzyme-linked immunosorbent assay ((ELISA) Crystal Chem, Inc., Elk Grove Village, IL, USA).

\section{Commercially Available Edible Marijuana Products}

Five commercially available edible marijuana products were selected for study. These products were made and sold at licensed stores throughout Colorado, USA. Participants were requested to purchase each of the identified products using their personal funds. Confirmation of purchase was verified by inspection of retail receipt. Features of each of the edible marijuana products are presented in Table 1. Each of the products contained $10 \mathrm{mg}$ of THC, except for the marijuana-free control product. The marijuana-free control product was provided by the research team (i.e. purchase by participants was not required). All products were consumed within 30 -seconds of self-administration. The order of self-administration was dictated by the research team based on a random generator.

\section{Reagents and Supplies}

THC, THC-COOH, THC-OH, THC-D3, THC-COOH-D3, and THC-OH-D9 were purchased from Cerilliant (Round Rock, TX, USA). A second set of THC, THC-OH, THC$\mathrm{COOH}$ were purchased from Lipomed (Cambridge, MA) to be used for quality control samples. Water and acetonitrile (LC-MS grade) were obtained from Millipore (Burlington, MA, USA). Dansyl chloride, sodium bicarbonate, sodium carbonate, acetic acid, and formic acid (LC-MSgrade) were obtained from Sigma-Aldrich (St. Louis, MO, USA). Captiva EMR-Lipid columns (1 mL, $40 \mathrm{mg}$ ) were purchased from Agilent Technologies (Santa Clara, CA, USA). 
Chromatography was performed with a Kinetex Phenyl Hexyl column $(3.0$ x 50 mm, $2.6 \mu \mathrm{m})$ purchased from Phenomenex Inc. (Torrance, CA, USA).

\section{Calibrators, Quality Controls, and Internal Standard Preparation}

Matrix matched calibrators and controls were prepared by the addition of appropriate volumes of methanolic stock standard mixes to $300 \mu \mathrm{L}$ of cannabinoid free plasma. Working standard mixes containing $0.01,0.1$, or $1.0 \mu \mathrm{g} / \mathrm{mL}$ of THC, THC-OH and THC-COOH were prepared from stock standards obtained from Cerilliant. They were used to produce calibrators for THC and THC-OH at $0.05,0.1,0.20 .5,1,5,10$, and $50 \mathrm{ng} / \mathrm{mL}$ and calibrators for THC$\mathrm{COOH}$ at $0.2,0.5,1,5,10$, and $50 \mathrm{ng} / \mathrm{mL}$. Quality control samples were prepared at $0.7,7$, and $20 \mathrm{ng} / \mathrm{mL}$ for each analyte using working standard mixes of $0.01,0.1$, or $1.0 \mu \mathrm{g} / \mathrm{mL}$ of THC, THC-OH and THC-COOH. These working standards were prepared from stock standard obtained from Lipomed to verify the calibrators prepared from Cerilliant stock standards. Quality control samples were run after every 20 subject samples with an expected accuracy of $+/-20 \%$. The internal standard mix solution contained $30 \mathrm{ng} / \mathrm{mL}$ THC-D3, $100 \mathrm{ng} / \mathrm{mL}$ THC-OH-D3, and $300 \mathrm{ng} / \mathrm{mL}$ THC-COOH-D9 in methanol.

\section{Cannabinoid Analysis by LC-MS/MS}

Plasma samples and matrix matched standards and quality controls were prepared for LCMS/MS analysis by protein precipitation, lipid removal, and derivatization with dansyl chloride. $10 \mu \mathrm{L}$ of internal standard solution was added to $300 \mu \mathrm{L}$ of plasma sample and mixed in a microcentrifuge tube. $900 \mu \mathrm{L}$ of acetonitrile containing $1 \%$ formic acid was added and vortexed for 30 seconds to precipitate proteins. Samples were centrifuged and supernatants transferred to Captiva EMR-Lipid columns for lipid removal. Using a positive pressure manifold, 3 psi of pressure was applied to the samples to elute through columns. Eluents were collected into a clean glass test tube and dried under nitrogen at $40^{\circ} \mathrm{C}$ prior derivatization. Dried eluents were reconstituted in $100 \mu \mathrm{L}$ of $1 \mathrm{mg} / \mathrm{mL}$ dansyl chloride in acetonitrile and transferred to autosampler vials fitted with $400 \mu \mathrm{L}$ glass inserts. $100 \mu \mathrm{L}$ of a $0.1 \mathrm{M}$ sodium carbonate-bicarbonate buffer (pH 10) was added and the sample incubated at $55^{\circ} \mathrm{C}$ for 20 minutes to derivatize the analytes. Samples were cooled to room temperature and neutralized with $10 \mu \mathrm{L}$ of acetic acid prior to LCMS/MS analysis.

Samples were analyzed with an Agilent 1290 UHPLC coupled to an Agilent 6460 triple quadruple mass spectrometer equipped with an Agilent Jet Stream electrospray ionization source (Agilent, Santa Clara, CA). Cannabinoids were first chromagraphically separated on a Phenomenex Phenyl Hexyl column $(3.0 \times 50 \mathrm{~mm}, 2.6 \mu \mathrm{m})$ held at $40^{\circ} \mathrm{C}$. A sample volume of 10 $\mu \mathrm{L}$ was injected and a mixture of water with $0.1 \%$ formic acid (A) and acetonitrile with $0.1 \%$ formic acid (B) at a flow rate of $0.4 \mathrm{~mL} / \mathrm{min}$. The gradient elution used was $40 \% \mathrm{~B}$ for 0.5 minutes, increasing to $80 \% \mathrm{~B}$ at 2 minutes, increasing to $100 \% \mathrm{~B}$ at 4.5 minutes, and held at $100 \%$ B for 1.5 minutes. The ionization source conditions used were as follows: positive polarity, nebulizer $45 \mathrm{psi}$; gas flow of $10 \mathrm{~L} / \mathrm{min}$ at $300^{\circ} \mathrm{C}$; sheath gas flow of $12 \mathrm{~L} / \mathrm{min}$ at $390^{\circ} \mathrm{C}$; capillary voltage of $3500 \mathrm{~V}$; nozzle voltage of $200 \mathrm{~V}$. The ion transitions monitored are displayed in Table 8 . Analytes were confirmed by retention time and the product ion ratio correlation between the sample peaks and corresponding standards $( \pm 20 \%)$. The data collection and processing were performed by using Agilent MassHunter Quantitative software (v.B.08.01). Quantitation was performed with linear regression using 8-point calibration curves from 0.05 $\mathrm{ng} / \mathrm{mL}$ to $50 \mathrm{ng} / \mathrm{mL}$ for THC and THC-OH. A 6-point calibration curves from $0.2 \mathrm{ng} / \mathrm{mL}$ to 50 
$\mathrm{ng} / \mathrm{mL}$ was used for THC-COOH. Analytical staff were naïve as to the edible marijuana products (i.e. blind to specific products and conditions).

Table 8. LC-MS/MS ion transitions monitored for danysl derivatives of cannabinoids in human plasma.

\begin{tabular}{|c|c|c|c|c|c|c|}
\hline Analyte Name & $\begin{array}{c}\text { Precursor } \\
\text { Ion }\end{array}$ & Product Ion & $\begin{array}{c}\text { Frag } \\
(\mathrm{V})\end{array}$ & $\begin{array}{l}\mathrm{CE} \\
(\mathrm{V}) \\
\end{array}$ & $\begin{array}{c}\text { Cell Acc } \\
(\mathrm{V})\end{array}$ & Polarity \\
\hline Dansyl-THC-COOH & 343.2 & 532 & 156 & 20 & 4 & Positive \\
\hline Dansyl-THC-COOH & 343.2 & 227 & 156 & 56 & 4 & Positive \\
\hline Dansyl-THC-COOH-D9 & 587.3 & 233 & 156 & 56 & 4 & Positive \\
\hline Dansyl-THC-COOH-D9 & 587.3 & 170 & 156 & 40 & 4 & Positive \\
\hline Dansyl-THC-OH & 564.3 & 241 & 139 & 64 & 4 & Positive \\
\hline Dansyl-THC-OH & 564.3 & 256 & 139 & 36 & 4 & Positive \\
\hline Dansyl-THC-OH-D3 & 567.3 & 241 & 139 & 64 & 4 & Positive \\
\hline Dansyl-THC-OH-D3 & 567.3 & 256 & 139 & 36 & 4 & Positive \\
\hline Dansyl-THC & 548.3 & 171 & 160 & 44 & 4 & Positive \\
\hline Dansyl-THC & 548.3 & 156 & 160 & 80 & 4 & Positive \\
\hline Dansyl-THC-D3 & 551.3 & 171 & 160 & 44 & 4 & Positive \\
\hline Dansyl-THC-D3 & 551.3 & 156 & 160 & 80 & 4 & Positive \\
\hline
\end{tabular}

Pharmacokinetic and Oral Glucose Tolerance Test Analysis

Pharmacokinetic analysis of the circulating concentrations of THC, THC-OH and THC$\mathrm{COOH}$ for each of the products was completed using dedicated software (PhoenixWinNonlin v8.3, Certara, NJ, USA). Areas under the concentration curves were calculated using the linear trapezoidal method.

Glucose and insulin data were processed using established methods. These included calculation of Homeostatic Model Assessment for Insulin Resistance (HOMA-IR) [46] and Matsuda Index [47]. Areas under the concentration curves for 2-hours (standard practice) and for 3.5 hours (practice specific to the current study) were calculated using the trapezoidal method.

\section{Statistical Analyses}

All data, unless otherwise stated, are expressed as mean and standard deviation.

Statistical calculations were performed using dedicated software (SigmaStat 3.0, Systat Software Inc., San Jose, CA, USA). Differences in circulating concentrations of THC, THC-OH and THC$\mathrm{COOH}$, glucose, and insulin over time and between products were examined using 2-way analysis of variance (ANOVA; product $x$ time), with repeated measures (time). Differences in the pharmacokinetic properties between the edible marijuana products were examined using 1way ANOVA, with repeated measures. When criteria for parametric statistics were not satisfied (i.e. normality and equal variance), a non-parametric alternative, Friedman Repeated Measures ANOVA on ranks, was used. Tukey tests were employed to further interrogate identified main effects. Relations between THC pharmacokinetic parameters and body size and composition values were explored using Pearson correlations. The level of statistical significance was set at $P<0.05$. 


\section{FUNDING:}

Stillwater Brands (Colorado, USA) provided financial support for this study.

\section{ACKNOWLEDGMENTS:}

We are grateful to Keith Woelfel and Marian Van Vlack for administrative and logistical support.

\section{AUTHOR CONTRIBUTIONS}

Conceptualization, T.R.E. and C.B.; Methodology, T.R.E. and C.B.; Formal Analysis, T.R.E., N.A., G.P.D., C.B.; Investigation, T.R.E., K.S.S.A., N.N.B.W., H.M.B., M.C.B., K.J.H., J.D.R., S.M.M., and C.B.; Resources, G.P.D. and C.B.; Data Curation, T.R.E., N.A., G.P.D., and C.B.; Writing - Original Draft Preparation, T.R.E., and C.B.; Writing - Review \& Editing, T.R.E., K.S.S.A., N.N.B.W., H.M.B., M.C.B., K.J.H., J.D.R., S.M.M., N.A., G.P.D., and C.B.; Resources, G.P.D. and C.B.; Visualization, T.R.E. and C.B.; Supervision, C.B.; Project Administration, C.B.; Funding Acquisition, C.B.

\section{INSTITUTIONAL REVIEW BOARD STATEMENT:}

The study was conducted according to the guidelines of the Declaration of Helsinki and approved by the Institutional Review Board of Colorado State University (Protocol \#20-10278H, $8^{\text {th }}$ of October 2020).

\section{INFORMED CONSENT STATEMENT:}

Informed consent was obtained from all subjects involved in the study.

\section{DATA AVAILABILITY STATEMENT:}

The data presented in this study are available on request from the corresponding author.

\section{CONFLICTS OF INTEREST:}

The authors declare no conflict of interest.

\section{REFERENCES}

1. Borodovsky, J.T.; Crosier, B.S.; Lee, D.C.; Sargent, J.D.; Budney, A.J. Smoking, vaping, eating: Is legalization impacting the way people use cannabis? Int J Drug Policy 2016, 36, 141-147, doi:10.1016/j.drugpo.2016.02.022.

2. Knapp, A.A.; Lee, D.C.; Borodovsky, J.T.; Auty, S.G.; Gabrielli, J.; Budney, A.J. Emerging Trends in Cannabis Administration Among Adolescent Cannabis Users. $J$ Adolesc Health 2019, 64, 487-493, doi:10.1016/j.jadohealth.2018.07.012.

3. Cao, D.; Srisuma, S.; Bronstein, A.C.; Hoyte, C.O. Characterization of edible marijuana product exposures reported to United States poison centers. Clin Toxicol (Phila) 2016, 54, 840-846, doi:10.1080/15563650.2016.1209761.

4. Richards, J.R.; Smith, N.E.; Moulin, A.K. Unintentional Cannabis Ingestion in Children: A Systematic Review. J Pediatr 2017, 190, 142-152, doi:10.1016/j.jpeds.2017.07.005. 
5. Wang, G.S.; Le Lait, M.C.; Deakyne, S.J.; Bronstein, A.C.; Bajaj, L.; Roosevelt, G. Unintentional Pediatric Exposures to Marijuana in Colorado, 2009-2015. JAMA Pediatr 2016, 170, e160971, doi:10.1001/jamapediatrics.2016.0971.

6. White, A.E.; Van Tubbergen, C.; Raymes, B.; Contreras, A.E.; Scallan Walter, E.J. Cannabis-Infused Edible Products in Colorado: Food Safety and Public Health Implications. Am J Public Health 2020, 110, 790-795, doi:10.2105/AJPH.2020.305601.

7. Kaczor, E.E.; Mathews, B.; LaBarge, K.; Chapman, B.P.; Carreiro, S. Cannabis Product Ingestions in Pediatric Patients: Ranges of Exposure, Effects, and Outcomes. J Med Toxicol 2021, 10.1007/s13181-021-00849-0, doi:10.1007/s13181-021-00849-0.

8. Newmeyer, M.N.; Swortwood, M.J.; Barnes, A.J.; Abulseoud, O.A.; Scheidweiler, K.B.; Huestis, M.A. Free and Glucuronide Whole Blood Cannabinoids' Pharmacokinetics after Controlled Smoked, Vaporized, and Oral Cannabis Administration in Frequent and Occasional Cannabis Users: Identification of Recent Cannabis Intake. Clin Chem 2016, 62, 1579-1592, doi:10.1373/clinchem.2016.263475.

9. Schlienz, N.J.; Spindle, T.R.; Cone, E.J.; Herrmann, E.S.; Bigelow, G.E.; Mitchell, J.M.; Flegel, R.; LoDico, C.; Vandrey, R. Pharmacodynamic dose effects of oral cannabis ingestion in healthy adults who infrequently use cannabis. Drug Alcohol Depend 2020, 211, 107969, doi:10.1016/j.drugalcdep.2020.107969.

10. Vandrey, R.; Herrmann, E.S.; Mitchell, J.M.; Bigelow, G.E.; Flegel, R.; LoDico, C.; Cone, E.J. Pharmacokinetic Profile of Oral Cannabis in Humans: Blood and Oral Fluid Disposition and Relation to Pharmacodynamic Outcomes. J Anal Toxicol 2017, 41, 8399, doi:10.1093/jat/bkx012.

11. Williams, N.N.B.; Ewell, T.R.; Abbotts, K.S.S.; Harms, K.J.; Woelfel, K.A.; Dooley, G.P.; Weir, T.L.; Bell, C. Comparison of Five Oral Cannabidiol Preparations in Adult Humans: Pharmacokinetics, Body Composition, and Heart Rate Variability.

Pharmaceuticals (Basel) 2021, 14, doi:10.3390/ph14010035.

12. Johansson, E.; Noren, K.; Sjovall, J.; Halldin, M.M. Determination of delta 1tetrahydrocannabinol in human fat biopsies from marihuana users by gas chromatography-mass spectrometry. Biomed Chromatogr 1989, 3, 35-38, doi:10.1002/bmc.1130030109.

13. Schlag, A.K.; O'Sullivan, S.E.; Zafar, R.R.; Nutt, D.J. Current controversies in medical cannabis: Recent developments in human clinical applications and potential therapeutics. Neuropharmacology 2021, 191, 108586, doi:10.1016/j.neuropharm.2021.108586.

14. Breijyeh, Z.; Jubeh, B.; Bufo, S.A.; Karaman, R.; Scrano, L. Cannabis: A ToxinProducing Plant with Potential Therapeutic Uses. Toxins (Basel) 2021, 13, doi:10.3390/toxins13020117.

15. Cuttler, C.; LaFrance, E.M.; Craft, R.M. A Large-Scale Naturalistic Examination of the Acute Effects of Cannabis on Pain. Cannabis and cannabinoid research 2020, 10.1089/can.2020.0068, doi:10.1089/can.2020.0068.

16. Buckley, M.C.; Kumar, A.; Swaminath, A. Inflammatory Bowel Disease and Cannabis: A Practical Approach for Clinicians. Adv Ther 2021, 10.1007/s12325-021-01805-8, doi:10.1007/s12325-021-01805-8.

17. Buchanan-Peart, K.R.; Oribhabor, G.I.; Khokale, R.V.; Nelson, M.L.; Cancarevic, I. Cannabis, More Than the Euphoria: Its Therapeutic Use in Drug-Resistant Epilepsy. Cureus 2020, 12, e9299, doi:10.7759/cureus.9299. 
18. Dell, D.D.; Stein, D.P. Exploring the Use of Medical Marijuana for Supportive Care of Oncology Patients. J Adv Pract Oncol 2021, 12, 188-201, doi:10.6004/jadpro.2021.12.2.6.

19. Sidney, S. Marijuana Use and Type 2 Diabetes Mellitus: a Review. Curr Diab Rep 2016, 16, 117, doi:10.1007/s11892-016-0795-6.

20. Penner, E.A.; Buettner, H.; Mittleman, M.A. The impact of marijuana use on glucose, insulin, and insulin resistance among US adults. Am J Med 2013, 126, 583-589, doi:10.1016/j.amjmed.2013.03.002.

21. Ngueta, G.; Ndjaboue, R. Lifetime marijuana use in relation to insulin resistance in lean, overweight, and obese US adults. J Diabetes 2020, 12, 38-47, doi:10.1111/17530407.12958.

22. Imtiaz, S.; Rehm, J. The relationship between cannabis use and diabetes: Results from the National Epidemiologic Survey on Alcohol and Related Conditions III. Drug Alcohol Rev 2018, 37, 897-902, doi:10.1111/dar.12867.

23. Barre, T.; Nishimwe, M.L.; Protopopescu, C.; Marcellin, F.; Carrat, F.; Dorival, C.; Delarocque-Astagneau, E.; Larrey, D.; Bourliere, M.; Petrov-Sanchez, V., et al. Cannabis use is associated with a lower risk of diabetes in chronic hepatitis $\mathrm{C}$-infected patients (ANRS CO22 Hepather cohort). J Viral Hepat 2020, 27, 1473-1483, doi:10.1111/jvh.13380.

24. Podolsky, S.; Pattavina, C.G.; Amaral, M.A. Effect of marijuana on the glucose-tolerance test. Ann NY Acad Sci 1971, 191, 54-60, doi:10.1111/j.1749-6632.1971.tb13986.x.

25. Hollister, L.E.; Reaven, G.M. Delta-9-tetrahydrocannabinol and glucose tolerance. Clin Pharmacol Ther 1974, 16, 297-302, doi:0009-9236(74)90441-X [pii].

26. Permutt, M.A.; Goodwin, D.W.; Schwin, R.; Hill, S.Y. The effect of marijuana on carbohydrate metabolism. Am J Psychiatry 1976, 133, 220-224.

27. Cinnamon Bidwell, L.; YorkWilliams, S.L.; Mueller, R.L.; Bryan, A.D.; Hutchison, K.E. Exploring cannabis concentrates on the legal market: User profiles, product strength, and health-related outcomes. Addict Behav Rep 2018, 8, 102-106, doi:10.1016/j.abrep.2018.08.004.

28. Bidwell, L.C.; Ellingson, J.M.; Karoly, H.C.; YorkWilliams, S.L.; Hitchcock, L.N.; Tracy, B.L.; Klawitter, J.; Sempio, C.; Bryan, A.D.; Hutchison, K.E. Association of Naturalistic Administration of Cannabis Flower and Concentrates With Intoxication and Impairment. JAMA Psychiatry 2020, 77, 787-796, doi:10.1001/jamapsychiatry.2020.0927.

29. Stott, C.G.; White, L.; Wright, S.; Wilbraham, D.; Guy, G.W. A phase I study to assess the single and multiple dose pharmacokinetics of THC/CBD oromucosal spray. Eur J Clin Pharmacol 2013, 69, 1135-1147, doi:10.1007/s00228-012-1441-0.

30. Feng, J.; Huang, M.; Chai, Z.; Li, C.; Huang, W.; Cui, L.; Li, Y. The influence of oil composition on the transformation, bioaccessibility, and intestinal absorption of curcumin in nanostructured lipid carriers. Food Funct 2020, 11, 5223-5239, doi:10.1039/d0fo00473a.

31. Lamsen, M.R.L.; Wang, T.; D'Souza, D.; Dia, V.; Chen, G.; Zhong, Q. Encapsulation of vitamin D3 in gum arabic to enhance bioavailability and stability for beverage applications. J Food Sci 2020, 10.1111/1750-3841.15340, doi:10.1111/1750-3841.15340. 
32. Jones, P.P.; Davy, K.P.; DeSouza, C.A.; van Pelt, R.E.; Seals, D.R. Absence of agerelated decline in total blood volume in physically active females. The American journal of physiology 1997, 272, H2534-2540.

33. Davy, K.P.; Seals, D.R. Total blood volume in healthy young and older men. J Appl Physiol 1994, 76, 2059-2062, doi:10.1152/jappl.1994.76.5.2059

34. Wong, A.; Montebello, M.E.; Norberg, M.M.; Rooney, K.; Lintzeris, N.; Bruno, R.; Booth, J.; Arnold, J.C.; McGregor, I.S. Exercise increases plasma THC concentrations in regular cannabis users. Drug Alcohol Depend 2013, 133, 763-767, doi:10.1016/j.drugalcdep.2013.07.031.

35. Wong, A.; Keats, K.; Rooney, K.; Hicks, C.; Allsop, D.J.; Arnold, J.C.; McGregor, I.S. Fasting and exercise increase plasma cannabinoid levels in THC pre-treated rats: an examination of behavioural consequences. Psychopharmacology (Berl) 2014, 231, 39873996, doi:10.1007/s00213-014-3532-3.

36. Westin, A.A.; Mjones, G.; Burchardt, O.; Fuskevag, O.M.; Slordal, L. Can physical exercise or food deprivation cause release of fat-stored cannabinoids? Basic Clin Pharmacol Toxicol 2014, 115, 467-471, doi:10.1111/bcpt.12235.

37. Farokhnia, M.; McDiarmid, G.R.; Newmeyer, M.N.; Munjal, V.; Abulseoud, O.A.; Huestis, M.A.; Leggio, L. Effects of oral, smoked, and vaporized cannabis on endocrine pathways related to appetite and metabolism: a randomized, double-blind, placebocontrolled, human laboratory study. Transl Psychiatry 2020, 10, 71, doi:10.1038/s41398020-0756-3.

38. Baggio, M.; Chong, A. Recreational marijuana laws and junk food consumption. Econ Hum Biol 2020, 39, 100922, doi:10.1016/j.ehb.2020.100922.

39. Peltonen, G.L.; Scalzo, R.L.; Schweder, M.M.; Larson, D.G.; Luckasen, G.J.; Irwin, D.; Hamilton, K.L.; Schroeder, T.; Bell, C. Sympathetic inhibition attenuates hypoxia induced insulin resistance in healthy adult humans. J Physiol 2012, 590, 2801-2809, doi:jphysiol.2011.227090 [pii]10.1113/jphysiol.2011.227090.

40. Oltmanns, K.M.; Gehring, H.; Rudolf, S.; Schultes, B.; Rook, S.; Schweiger, U.; Born, J.; Fehm, H.L.; Peters, A. Hypoxia causes glucose intolerance in humans. Am J Respir Crit Care Med 2004, 169, 1231-1237, doi:10.1164/rccm.200308-1200OC 200308-1200OC [pii].

41. Bethel, M.A.; Price, H.C.; Sourij, H.; White, S.; Coleman, R.L.; Ring, A.; Kennedy, I.E.; Tucker, L.; Holman, R.R. Evaluation of a self-administered oral glucose tolerance test. Diabetes Care 2013, 36, 1483-1488, doi:10.2337/dc12-0643.

42. Beals, J.W.; Binns, S.E.; Davis, J.L.; Giordano, G.R.; Klochak, A.L.; Paris, H.L.; Schweder, M.M.; Peltonen, G.L.; Scalzo, R.L.; Bell, C. Concurrent Beet Juice and Carbohydrate Ingestion: Influence on Glucose Tolerance in Obese and Nonobese Adults. J Nutr Metab 2017, 2017, 6436783, doi:10.1155/2017/6436783.

43. Palomares, B.; Ruiz-Pino, F.; Garrido-Rodriguez, M.; Eugenia Prados, M.; SanchezGarrido, M.A.; Velasco, I.; Vazquez, M.J.; Nadal, X.; Ferreiro-Vera, C.; Morrugares, R., et al. Tetrahydrocannabinolic acid A (THCA-A) reduces adiposity and prevents metabolic disease caused by diet-induced obesity. Biochem Pharmacol 2020, 171, 113693, doi:10.1016/j.bcp.2019.113693.

44. Panee, J.; Gerschenson, M.; Chang, L. Associations Between Microbiota, Mitochondrial Function, and Cognition in Chronic Marijuana Users. J Neuroimmune Pharmacol 2018, 13, 113-122, doi:10.1007/s11481-017-9767-0. 
45. Berk, K.; Bzdega, W.; Konstantynowicz-Nowicka, K.; Charytoniuk, T.; Zywno, H.; Chabowski, A. Phytocannabinoids-A Green Approach toward Non-Alcoholic Fatty Liver Disease Treatment. J Clin Med 2021, 10, doi:10.3390/jcm10030393.

46. Matthews, D.R.; Hosker, J.P.; Rudenski, A.S.; Naylor, B.A.; Treacher, D.F.; Turner, R.C. Homeostasis model assessment: insulin resistance and beta-cell function from fasting plasma glucose and insulin concentrations in man. Diabetologia 1985, 28, 412-419, doi:10.1007/bf00280883.

47. Matsuda, M.; DeFronzo, R.A. Insulin sensitivity indices obtained from oral glucose tolerance testing: comparison with the euglycemic insulin clamp. Diabetes Care 1999, $22,1462-1470$. 